\title{
Speeding Sustainable Development: Integrating Economic, Social, and Environmental Development
}

\section{Charles Kenny}

\section{Abstract}

This paper discusses the role for policy integration to speed progress towards delivering the Sustainable Development Goals (SDGs). This is required because the goals set very ambitious targets for progress across a range of interlinked areas, encompassing both synergies and tradeoffs. Lessons of policy integration at the national level suggest that it is usually at best partially successful, requiring significant commitment from the highest levels of government. Policy integration regarding foreign affairs has proven even more challenging. This paper suggests a mechanism for prioritizing coordination and the use of coordination tools including regulation, safeguards, taxes, and subsidies. It also suggests re-orienting ministerial responsibilities where possible from input control to achievement of outcomes as well as tools to promote innovation by subnational governments and the private sector.

Keywords: SDGs, sustainable development, policy coordination

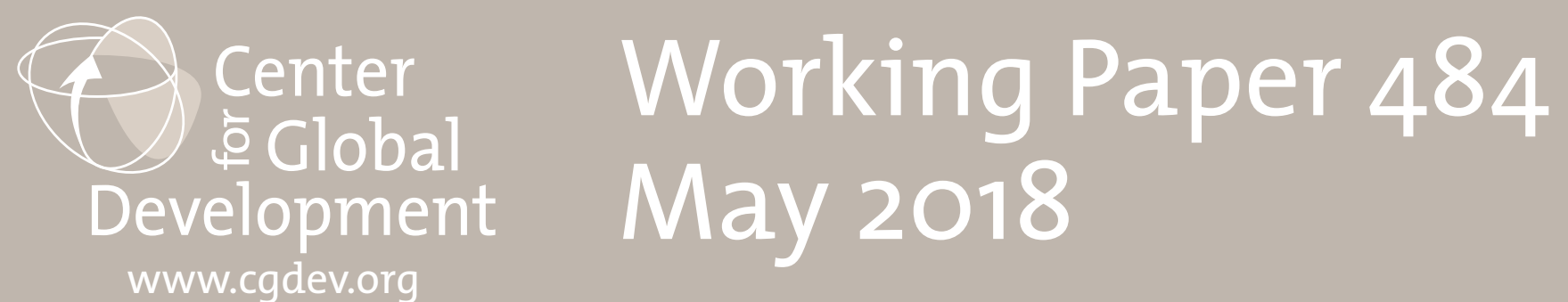




\title{
Speeding Sustainable Development:
}

\section{Integrating Economic, Social, and Environmental Development}

\author{
Charles Kenny \\ Center for Global Development
}

Thanks to the United Nations Department of Economic and Social Affairs for support and to Masood Ahmed, Alan Gelb, Brian Levy, and staff at UNDESA including Joop Theunissen for comments.

Charles Kenny, 2018. "Speeding Sustainable Development: Integrating Economic, Social, and Environmental Development." CGD Working Paper 484. Washington, DC: Center for Global Development. https://www.cgdev.org/publication/speeding-sustainabledevelopment-integrating-economic-social-and-environmental

Center for Global Development 2055 L Street NW Washington, DC 20036

202.416.4000

(f) 202.416 .4050

www.cgdev.org
The Center for Global Development is an independent, nonprofit policy research organization dedicated to reducing global poverty and inequality and to making globalization work for the poor. Use and dissemination of this Working Paper is encouraged; however, reproduced copies may not be used for commercial purposes. Further usage is permitted under the terms of the Creative Commons License.

The views expressed in CGD Working Papers are those of the authors and should not be attributed to the board of directors, funders of the Center for Global Development, or the authors' respective organizations. 


\section{Contents}

I. Introduction: The Need for Integration and Innovation.................................................... 1

The SDGs Call for Historically Unprecedented Global Progress across a Range of Economic, Social, and Environmental Areas. ....................................................................... 1

The Goals and Underlying Targets Are Strongly Interconnected, Involving Both Synergies and Tradeoffs... .................................................................................................. 2

... As Well as a Considerable Number of Regional and Global Public Good Issues....... 4

The Progress Suggested Requires Greater Policy Integration and Innovation. ................. 5

II. Policy Integration at the National and International Levels ................................................. 7

A. The Challenge of Silos to Delivering Sustainable Development..................................... 7

B. Lessons of Policy Integration at the National Level........................................................ 8

C. Policy integration at the international level .................................................................. 14

D. Cross-Sectoral and Global Cost Benefit Analyses.........................................................15

III. The Way Forward for Strategies and Policy Integration in Support

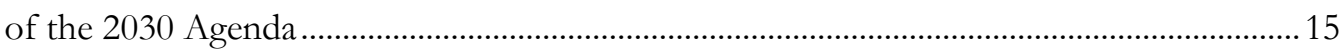

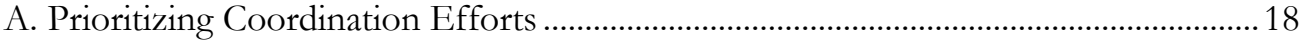

B. Managing Prioritization and Tradeoffs .............................................................................19

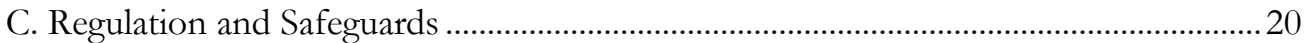

D. Making Taxes and Subsidies Work for Sustainable Development ...............................2 21

E. Re-orienting Ministries from Inputs to Outcomes ...........................................................2 24

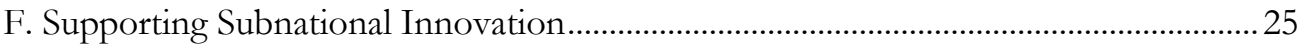

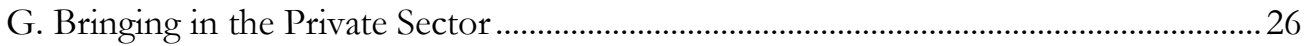

H. Global Commitment to Policy Integration..............................................................2 27

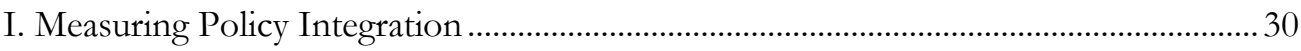

J. Data for Integration and Innovation .................................................................................. 33

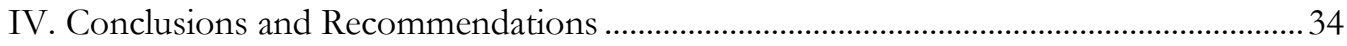

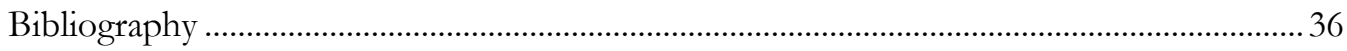

Annex 1: Correlation between SDG Index Components......................................................... 42

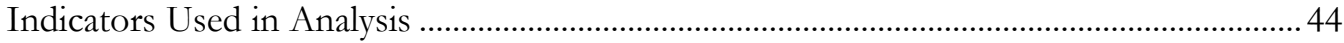




\section{Introduction: The Need for Integration and Innovation}

\section{The SDGs Call for Historically Unprecedented Global Progress across a Range of Economic, Social, and Environmental Areas.}

The United Nations Sustainable Development Goals are the most ambitious set of global development goals ever agreed. Amongst other things, by 2030 they call for an end to poverty hunger and malnutrition everywhere; full and productive employment and decent work for all; universal health coverage; eradication of AIDS, tuberculosis, malaria, and neglected tropical diseases; universal secondary education and housing, water, sanitation, modern energy, and communications technology access for all. All of this progress will need to occur as global populations climb towards 9 billion by 2050, food and water demands increase by more than 50 percent, energy demand by over 80 percent and the world economy may be four times its current size (OECD 2015).

In many of these cases, the Goals demand historically unprecedented rates of change for some countries. Take the child mortality target, to reduce rates of mortality to below 25 per 1,000 live births in every country. The World Bank reports that 24 countries had a child mortality rate more than three times that level in 2015. Amongst the countries that had a child mortality rate of over 75 , the average decline in mortality over the past fifteen years was an impressive 46 percent. But if high-mortality countries only matched that rate of progress over the next fifteen years, they would all miss the SDG target. Rwanda achieved the fastest rate of reduction amongst high-mortality countries between 2000-2015: a stunning 77 percent decline. But even if all high mortality countries managed to equal that performance over the next fifteen years, six countries would still miss the SDG target for $2030 .{ }^{1}$

And because of the SDG's broad scope, the progress demanded is very wide ranging- not just economic but also social and environmental. From this point of view the child mortality target is comparatively straightforward: we know the technical solutions to reducing mortality, and we have well-tested approaches that have been rolled out in many countries. For other targets we lack the experience and data to know what works where and how fast. And meeting a number of the targets implies shifting attitudes and norms (towards gender, for example) at a dramatic rate.

The progress suggested will be expensive. Schmidt-Traub (2015) suggests that to meet the SDGs in low and middle income countries might involve expenditures worth 11.5 percent of their GDP at market exchange rates.

But even more than the cost, meeting the SDGs will require dramatic policy change. Take education: The MDGs focused on getting children into classrooms-a largely successful global effort to ensure every child completed primary school. The SDGs have added an emphasis on children actually learning something while they are in class, and this requires far

\footnotetext{
${ }^{1}$ Data from http://databank.worldbank.org/data/reports.aspx? source=2\&series=SH.DYN.MORT\&country=\# accessed $7 / 8 / 2016$
} 
more than finance. Between 2007 and 2011, India increased expenditure on elementary education by 80 percent, but average learning outcomes reported by independent surveys declined - the fraction of grade 8 children who could do division fell from 70 percent to 57 percent (Pritchett et. al., 2013).

The problem of low learning despite schools being built and teachers hired is widespread. Surveying countries home to 40 percent of Sub Saharan Africa's population, Bold et al (2016) find that only 14 percent of fourth graders can read a paragraph of text, a figure as low as 6 percent in Nigeria. Only one in five Nigerian fourth graders can put numbers in numerical order. Very low learning gains in school will be in part because only one in four Nigerian teachers have mastery of the fourth grade curriculum. Very rapid change in learning outcomes appears a rare phenomenon and the evidence base on how to achieve it is weak.

There is a similar story with health systems: a survey of health practices in rural Madhya Pradesh in India found 67 percent of health care providers had no medical qualifications at all. But even trained doctors did not practice what they knew: there were only small differences between trained and untrained doctors in adhering to clinical checklists (there was slightly higher adherence in private practice). Correct diagnoses were rare, and incorrect treatments were widely prescribed (Das et al 2012). This is why there can be a considerable gap between providing universal health care and improving health outcomes. ${ }^{2}$ Again, changing such outcomes is about far more than money - it is about incentives and systemic reform.

\section{The Goals and Underlying Targets Are Strongly Interconnected, Involving Both Synergies and Tradeoffs...}

Adding to the challenge, but also to the potential for progress, is the fact that the goals and targets are deeply interconnected. The SDG targets around jobs are a prime example of a progress area that has multiple causes across sectors. The World Bank (2013) suggests factors including good nutrition, health and education, distortionary policy interventions, infrastructure and finance, land reform and trade integration can all play a role- the jobs agenda is truly cross-cutting. Again, forest conservation can significantly reduce the rate of climate change, provide soil protection and water regulation services, reduce waterborne disease, improve water supply, reduce the impact of floods and preserve biodiversity (Mullan, 2014). ${ }^{3}$

This type of interlinkage is recognized within the Goals themselves: LeBlanc (2015) notes that 60 SDG targets explicitly refer to at least one other goal than the one to which they

\footnotetext{
${ }^{2}$ Two recent studies in India have suggested just how bad the quality of health care is there -one found that moving births into hospitals wasn't improving maternal or neonatal mortality rates. Another found that public primary health care providers were more qualified and cost four times more than private providers but private providers did as well or better in delivering health care.

${ }^{3}$ Beyond its direct contribution to a number of different SDGs, economic analysis suggests these benefits are often far more financially valuable than the revenues extracted from deforestation and farming
} 
belong. And four goals contain targets that refer to more than ten different other goals (sustainable consumption, inequality, poverty and sustained, inclusive economic growth). ${ }^{4}$

For the same reason, policy changes will frequently impact multiple targets: for example, reducing inequality will involve greater equality of opportunity-this is also a tool for productivity and equality of outcomes. Interlinkages between both targeted SDG outcomes and the policies used to achieve them call for the adoption of a multisectoral response to sectoral targets.

In particular, the interlinkages imply that, in some cases, the most effective way to promote progress towards a sustainable development goal in a particular sector may involve interventions in other sectors. A case in point is that non-health sector interventions in energy, water and sanitation can have a dramatic impact on health. Limiting open field defecation in India, for example, dramatically reduces stunting as well as having knock-on effects on learning and adult incomes (Hammer and Spears 2016). Clean energy can dramatically reduce illness and death from air pollution, while clean water can dramatically reduce death from gastro-intestinal conditions (Schmidt-Traub, 2015). In education, Hassan and Lucchino (2014) find that giving solar lamps to $7^{\text {th }}$ grade pupils in rural Kenya leads to impressive increases in test scores. Same language subtitling, which displays text of the words being spoken or sung on television along the bottom of the screen, costs fractions of a cent per viewer, but as much as doubled literacy gains amongst students exposed in India (Kothari et al 2002).

For all the opportunity to exploit synergies between SDG targets by using a cross-sectoral approach, there are also potential tradeoffs between them. Not least, as meeting the SDGs will require considerable investment, there is the simple tradeoff that in an environment of constrained resources, investments in pursuit of one SDG target may crowd out investments in pursuit of another one. One recent estimate suggests meeting the health, education, social protection, water and sanitation and nutrition targets might cost a minimum of $\$ 500$ per capita (PPP) in the poorest countries (although note again, there is considerably more to delivering on the SDG targets in these areas than funding, as was demonstrated in the MDG period-Kenny and Sumner, 2011). This compares to current basic service expenditures of approximately $\$ 222$ per capita in LDCs. Meeting that gap in LDCs would cost $\$ 152$ billion a year (ONE, 2015).

This financing would need to come from higher taxes (and so reduced private consumption and investment), moving government expenditure from other areas that contribute to meeting the SDGs or absorption of the considerable majority of current international aid flows. Again, African countries in particular have already committed to provide 15 percent of government spending to health, 20 percent to education, and 10 percent to agriculture.

\footnotetext{
${ }_{4}^{4}$ There can be spillover effects from interventions covering particular targets within thematic or sectoral areas: In India, a 1993 law reserved leadership positions for women in randomly selected village councils. In villages where the reservations took place, the gender gap in educational attainment was erased and girls spent less time on household chores. The gender gap in career aspirations also considerably shrunk (Beaman et al 2012).
} 
This leaves only 55 percent for all other government activities including social protection, infrastructure, security, justice, regulation and the environment, for example.

But there are also tradeoffs in that progress on some targets may push regress in others because of negative externalities between them. These tradeoffs are well illustrated by existing institutions that have mandates involving multiple pillars of sustainable development. For example, the US Bureau of Land Management has a mission to "sustain the health, diversity, and productivity of America's public lands for the use and enjoyment of present and future generations." 5 That mandate suggests elements of all three components of sustainable development, and it mires the bureau in painful conflict not least between those more concerned with the jobs and output linked to the land it manages and those more concerned with environmental stewardship (see, for example, Noon, and McKelvey, 1996).

The UN Environment Program suggests all 17 SDGs imply competition for resources, while progress towards 12 of them is directly related to the sustainable use of resources, including land, food, water, energy, and materials (International Resource Panel, 2015). ${ }^{6}$ Reducing the scale of tradeoffs will require active policy intervention—not least, support for the development and rollout of low-emission energy sources to meet the modern energy, poverty, jobs and economic growth targets without severe repercussions on the health, climate and oceans targets. But tradeoffs will remain, and an important part of a policy integration process would be to manage them in a way that maximizes overall progress.

\section{... As Well as a Considerable Number of Regional and Global Public Good Issues.}

The energy and climate example also highlights the fact that questions of tradeoffs can cross borders. On the production side, it is increasingly clear that we cannot extract all fossil fuel reserves worldwide without significant climate impacts, but that raises the question of which reserves in which countries are left in the ground. On the consumption side, the world's poorest people are responsible for a very small proportion of emissions and should not bear the cost of the shift to low-emissions energy infrastructure.

Positive externalities also cross borders. Furthering the sustainable development prospects of other countries is not (only) an act of altruism, let alone charity, it is an act of self interest. National economic prospects are increasingly tied to the health of the global economy, and this is particularly true of the developed world-more than half of US exports, for example, are destined for the developing world, and the country depends on healthy growth in those markets to expand trade opportunities (Kenny, 2014). This is to say nothing of the fact that reducing climate change will require action from major economic powers from the US, Europe, China (the world's largest emitter), India and beyond; the preservation of global

\footnotetext{
${ }^{5}$ See http://www.blm.gov/wo/st/en.html

${ }^{6}$ Again, in the area of trade, increased regulation around environmental standards may also have a chilling effect on imports, perhaps particularly from low income countries (UNCTAD 2015).
} 
biodiversity requires the involvement of countries home to particularly rich biomes including Indonesia, Madagascar and Brazil; and controlling the emergence of new infectious disease threats involves cooperation from countries home to animal reservoirs, significant factory farming and widespread antibiotic prescription to take just three more examples of global public good issues.

Despite this, as well as failing to coordinate on global public good provision, countries frequently follow beggar-thy-neighbour strategies that can considerably constrain global welfare and often have their biggest impact on poor people. These involve barriers to migration, trade and finance as well as subsidies for industry and agriculture. As a recent OECD Policy Brief on policy coherence suggested, for example, the fact that OECD countries provide production subsidies to farmers while encouraging developing countries to export agricultural produce to world markets "makes little economic sense" (OECD, 2008). A dated global estimate from the Word Trade Organization is that subsidies of all types were worth around $\$ 300$ billion worldwide in $2003 .{ }^{7}$ While some of these subsidies might be justified on the grounds of environmental or social benefit, the considerable majority will involve incentives with negative spillovers in terms of economic, social or environmental impacts including fossil and biofuel subsidies and incentives to move or retain industries.

\section{The Progress Suggested Requires Greater Policy Integration and Innovation.}

A recent effort to measure levels of achievement towards SDG targets finds, overall, a very close link between levels of achievement and traditional measures of development, suggesting developed countries as a rule a far closer to achieving the SDGs than poor countries (Sachs et. al., 2016). Economic growth especially in the poorest countries will be vital to provide the resources required for investments across SDG targets. But even considerably surpassing the ambitious growth target in SDG Goal 8, which suggest around 4.5 percent per capita growth in the poorest countries, those countries will remain very poor. Over fifteen years, the target growth rate suggests a doubling of average incomes. Compared to the fifty-fold income gaps between the world's poorest countries (around \$1,000 PPP and below) compared to its richest ( $\$ 50,000$ and above), a doubling is a fairly small move up the income tangent. This alone suggests the need for a greater "decoupling" of economic growth and broader progress if lower-income countries are to achieve the SDGs.

In the past, we have seen considerable progress on health and school enrolment even in countries seeing no growth (Kenny, 2012). Decoupled social progress needs to become far more rapid in the SDG era if we are to meet the social targets. And there are, of course, exceptions to the positive link between SDG targets and overall development: the world's richer countries are responsible for an outsized share of global carbon emissions. Once

\footnotetext{
${ }^{7}$ https://www.iisd.org/gsi/sites/default/files/GSI_Investment Incentives.pdf, accessed 8/26/2016
} 
again, a decoupling of the relationship between emissions and domestic production is required.

This decoupling will involve more efficient conversion of resources into development results through a focus on cost-effective solutions as well as new technologies. And this will involve public and private innovation in delivery mechanisms alongside policy coordination. With regards to innovation, as the energy and environment case highlights, we do not have the technologies at hand to plausibly deliver broad-based sustainable development across goal areas at the speed suggested by the SDGs. The same applies to policy innovation: it is more than applying best practices, we need to figure out what they are for a given context. Policy reforms which improve targeting and reduce incentives to pollute or discriminate, or regulations that achieve similar levels of environmental benefit at a lower social or economic cost, will allow for more rapid progress in overall sustainable development.

But it is increasingly clear that "best practice" policies are only best practice for particular institutions at particular times (Levy, 2014, Pritchett et al 2013). A recent study of aid impact evaluations looked at the impact of similar projects in different contexts. The analysis suggests dramatic variance, with orders of magnitude differences in results measured across similar interventions (as it might be, school feeding programs). This suggests the vital importance of local context to the impact of government programs and the need for considerable local monitoring and evaluation to discover relevant best practice rather than relying on "global best practice" (Vivalt 2015). And that suggests the need for data: we need to measure the efficacy of policy innovation in local settings not just "tracking the SDGs data" but "local feedback" data

In turn, this suggests the most effective policies to speed progress towards particular targets while maximizing the net positive spillovers on other targets will require continual innovation across countries to achieve outcomes at historically unprecedented rates. To take two examples mentioned earlier: in order to achieve universal functional literacy or end preventable child deaths in only fifteen years, education and health systems worldwide will need to see dramatic policy experimentation and innovation to achieve previously unmatched rates of progress.

More broadly, compared to the MDG targets, which were clear, simple, single-issue and relatively few in number, the SDG targets are more far reaching in number, complexity, reach and transformative demands. They "will require a fundamental changes in the way policymaking takes place in countries, rather than simply an alignment of resources and development coordination with targets," suggests UNDESA. This will include a policy integration process that encompasses problem definition, policy formulation, implementation and evaluation. (UNDESA, 2015)

LeBlanc (2015) suggests the SDGs themselves may be a valuable force for this integration: "links among goals through targets may also facilitate real mainstreaming of dimensions that previously suffered from not having strong sectoral anchoring" he writes, although noting "there are many more scientifically meaningful connections among goals than are explicitly 
reflected in the SDGs" suggesting the need for further analysis of the most significant interactions.

The rest of this paper discusses previous exercises in policy integration from Poverty Reduction Strategy Papers through European Union Sustainable Development Strategies and discusses what we can say about their impact and lessons learned. It suggests that strategies and policy change to achieve the SDGs will need to go far further, involving a rehaul of what Ministries see as their role, but still based on realism about what integration can achieve. It lays out some policies that may help meet some of the major challenges of integration and suggests national and international institutions that will allow policy innovation to become an ongoing part of government operation. It is doubtful such changes would be sufficient to meet the SDGs, and even more doubtful that they will be widely implemented, but it is unlikely the targets will be met without far more effective policy coordination aimed at delivering sustainable development.

\section{Policy Integration at the National and International Levels}

\section{A. The Challenge of Silos to Delivering Sustainable Development}

The role of prioritization amongst competing goals and interests is not only a key function of governance, it is the inevitable practice of Treasury Departments deciding on tax and funding priorities and Parliaments passing budgets. And the concept of policy integration is not a new one, either-although sometimes known by different terms (policy coherence, consistency or co-ordination, holistic or joined-up government, cross-cutting policy-making and concerted decision-making are related or synonymous terms listed by Meijers and Stead, 2004). Agenda 21 suggested that "prevailing systems of decision-making in many countries tend to separate economic, social and environmental factors at the policy, planning and management levels," 8 and this remains a significant issue a quarter century later. The Agenda called for national strategies for sustainable development alongside a coordination structure to support implementation.

That said, at a time of growing recognition of the linkages between various development challenges that cross both traditional departmental lines as well as levels of government from the local to the global, the issue of policy coordination has taken on a new urgency. The UN Economic and Social Council recently concluded that "insufficient understanding and accounting for positive synergies and negative trade-offs across sectors have resulted in incoherent policies, adverse impacts of development policies focused on specific sectors on other sectors, and ultimately in diverging outcomes and trends across broad objectives for sustainable development" (ECOSOC, 2016).

\footnotetext{
${ }^{8}$ See https://sustainabledevelopment.un.org/content/documents/Agenda21.pdf
} 
The diffusion of power may have made the coordination challenge even greater: New Public Management approaches have seen the further disaggregation of ministries into service delivery agencies while a strong global trend towards decentralization has moved power to lower levels of government. Meanwhile, the growth of global supply chains and cross border financial flows has strengthened global players perhaps to the detriment of national governments. At a time where the number and importance cross-cutting issues appears to be on the rise, this can pose an additional challenge to meeting system-wide objectives (Berger and Steurer, 2009).

The discussion of integrating sustainable development into government-wide policymaking has often taken as a starting assumption that the greatest challenge is integrating environmental concerns (Berger and Steurer 2009). This on the grounds that there are already considerable interests and powerful institutions concerned with economic development (including treasury and finance departments) and social development (education, health and welfare ministries). This compares to traditionally weak, comparatively young ministries of environment. The challenge for the SDGs is even bigger - it involves incorporating not just negative but also positive externalities and maximizing progress across the economic, social and environmental pillars of sustainable development at the national and global level.

The OECD (2015) suggests that policy coherence for the post-2015 agenda entails "Addressing in a balanced manner the economic, social, and environmental dimensions of sustainable development in policy making; considering more systematically what matters for well-being... for people living elsewhere; and adopting a long-term perspective" The goal of coherence is to foster synergies across policy areas, identify tradeoffs and address international spillovers.

\section{B. Lessons of Policy Integration at the National Level}

Meijers and Stead (2004) suggest a number of process elements that are common to recommendations for better policy coordination including high-level commitment, a strategic policy framework, central overview and coordination capacity, a source of good analysis regarding tradeoffs, mechanisms to anticipate and resolve policy priorities and budgetary imperatives, and monitoring mechanisms. A number of countries have attempted to introduce elements of this policy coordination regime through strategies and related institutions in the past.

\section{i. Safeguards}

A minimal level of policy coordination involves safeguards - ensuring laws, policies and investments do not broach fundamental human rights or wreak considerable (and uncompensated) social or environmental damage. Constitutional protections have a core role in this regard. Safeguard policies can require ex ante review of social and environmental impacts as part of investment decision-making and can play a valuable role in redesigning or abandoning projects likely to do considerable harm. The ongoing and contentious review of World Bank safeguards policies suggests the limits to such exercises, however: they focus on 
negative externalities, at the level of a project or policy rather than at the macro level, they cause considerable delay and carry a considerable institutional burden and (arguably) they still allow through projects which should be stopped. ${ }^{9}$

\section{ii. "Mainstreaming"}

Mainstreaming has usually involved exhortation to consider gender impacts across all investments on top of the mandatory screening under safeguards policies. The United Nations' own mainstreaming effort has involved integrating gender equality in strategies, policies, programming processes, auditing and communication, and has seen progress over the last few years in the number of strategy and policy documents alongside processes that include a gender equality component (United Nations 2015).

While such mainstreaming efforts are important in bringing issues of gender equality into the limelight and ensuring they are discussed, the impact on outputs and outcomes can be more muted. In the World Bank, while mainstreaming has led to a dramatic uptick in the mention of gender in project documents, it has had a lesser effect on measuring inputs disaggregated by gender, and an even smaller effect on measuring project outcomes or significantly altering project design. And projects specifically focused on gender-related development issues remain a very small part of total portfolios. A greater level of regulatory requirement or incentives to incorporate gender concerns may have a larger impact, and some agencies have gone beyond exhortation to provide some incentive to team leaders to incorporate gender concerns more centrally - the European Bank for Reconstruction and Development, for example, includes project incorporation of gender components as part of the package of actions linked to performance related pay for project managers (Buvinic et al 2016, Kenny and O’Donnell 2016).

\section{iii. PRSPs and MDG Strategies and Coordination Units}

Going beyond safeguards and approaches that help highlight a particular overlooked development agenda are broader strategy documents. Poverty Reduction Strategy Papers are one example. A World Bank/IMF review of the 49 countries that had launched Poverty Reduction Strategy Papers by 2005 suggests that it would be impossible to link PRSPs to particular reductions in poverty. It argued, however, that when well implemented, the PRSP approach could provide a framework to bring coherence to setting and implementing national priorities around pro-poor development and aligning donor support. ${ }^{10}$

According to Grindle (2004) Poverty Reduction Strategy Papers were a useful effort to develop a cross-cutting strategy to tackle poverty and to engage stakeholders. They involved the creation of mechanisms for consultation and coordination including national steering committees or national policy councils. These mechanisms frequently included a secretariat and/or technical support as well as national workshops and participatory evaluations. And

\footnotetext{
${ }_{9}^{9}$ See, for example https://business-humanrights.org/en/world-banks-draft-safeguards-drastically-weaken-socialenvironmental-protection-say-civil-society-groups accessed 7/29/2016

${ }^{10}$ https://www.imf.org/external/np/pp/eng/2005/091905s.htm
} 
the arrangement was a novelty in many countries. Amongst other benefits, this drew traditionally weak social service ministries into cross-government discussions alongside consultations with civil society organizations. In particular, participatory processes regularly pointed to major weaknesses in service delivery, indicating that "implementation of national policies was more often the problem than the contents of the polices." This was subsequently recorded in poverty reduction strategy documents, but (sadly) ill-reflected in the resulting strategies, suggests Grindle.

Again, in the particular area of governance and tradeoffs which are at the heart of policy integration efforts, Poverty Reduction Strategy Papers "paid very little attention, if any, to the issue of checks and balances among branches of government, beyond concerns about strengthening the judicial process. By and large, checks and balances in the management of public resources were addressed by committing to executive based action with regard to public expenditure management and information provision" (Grindle, 2004). Grindle warns this same danger applies to policy integration efforts in support of an overarching sustainable development strategy: a technocratic "coordination" solution does not reflect the need for checks and balances in a system that respects both rights and different stakeholder opinions. Setting priorities is "a multidimensional exercise, involving discussions of more technical issues such as sequences and degrees of administrative difficulty as well as tradeoffs among country-specific needs and capacities, interests, and political benefits" (Grindle, 2004).

During the period of MDG implementation, a number of countries set up national coordination committees, desks or units in central ministries or Presidencies to mainstream and harmonize efforts to achieve the Goals. In the case of Kenya, a stakeholder survey suggests respondents felt the MDGS Project Implementation Unit played a beneficial role in supporting coordination and planning through integrating the MDGs into national planning - and that the Unit could play a similar role with the SDGs (Save the Children, 2016).

That said, it is worth noting that there is not an analysis of the impact of coordination on rates of progress towards MDG targets and overall, across countries, the relationship between MDG adoption and more rapid progress is contested (Kenny and Sumner, 2011). The levels of coordination and integration achieved with the MDGs were certainly not enough to achieve MDG targets despite increased domestic and international funding, all of which suggests the need for some realism over what policy integration and policy coordination bodies will be able to achieve in terms of meeting the SDGs unless radically more transformative efforts are undertaken (some ideas for which are suggested below).

\section{iv. Sustainable Development Strategies}

As early as 2003, more than a third of the world's countries had initiated or developed a sustainable development strategy, responding to the call for such strategies from the 1992 Rio Earth Summit. However, a review by James Meadowcroft (2007) concluded that "evidence suggests that even when SD strategy processes get underway, they typically remain marginal to the core activities of government." Reasons for this include that the legal 
underpinnings of many strategies were weak, institutional ownership rested solely with the environment agency, coordination and feedback mechanisms were weak or absent, quantifiable targets were few and integration with fiscal policy absent. Meadowcroft concludes that in order to make strategies have greater impact, they should clearly delineate priorities and domains where development patterns deviate furthest from sustainable development, they should be "owned" by central government departments and integrated with financial routines including the annual budget cycle, they should be subject to measurement, monitoring and auditing, and should coordinate with local government.

The European Union Sustainable Development Strategy suggests that all major European and Member State policy decisions should undergo a high-quality impact assessment covering economic, social and environmental ramifications (Berger and Steurer, 2009). It has led to the adoption of national strategies by EU member countries. Nordbeck and Steurer (2015) review the history of integrated multi-sectoral sustainable development strategies in Europe and conclude the greatest success of SD strategies may have been as communications and engagement tools. "SD strategies as policy documents aim to reconcile the three pillars of SD but fail to actually balance or better integrate them, no matter which approach they follow... They do not address (let alone overcome) trade-offs between different (often sectoral) objectives..."

Regarding sustainable development impact, a broad set of policies in the European Unionsome of which were related to the elevation of sustainable development concerns-has seen the block move towards a domestic "decoupling" of economic growth, domestic resource use and carbon dioxide output. But it is worth noting this is in considerable part counterbalanced by importing resource-intensive goods from elsewhere, suggesting limited impact on global sustainability (Wiedmann et al. 2013).

Reasons for this limited impact include that the link between monitoring indicators and policy proposals was weak; "most SD strategies include a wide range of topics and do not emphasize priorities," and so "policymakers were able to cherry pick those aspects that served their interests best...;" and "target setting in SD strategies does not follow a problemdriven rationale but mainly a political logic that co-opts policies that would have been formulated anyway." A later review suggested that most strategies "represent a vision-based approach with vague objectives that are usually neither new nor ambitious." (Nordbeck and Steurer, 2015). In 2014, for example, Denmark launched a national strategy for sustainable development including 23 targets and indicators and a monitoring framework to capture progress on social, economic and green sustainability. But according to a Save the Children review (2016) "in practice it became a catalogue of policies that were established prior to its development."

Regarding policy formulation, major decisions were usually taken without reference to strategy and even where coordination for strategy implementation was overseen by relatively senior government officials "SD strategies simply lack the political grip necessary for noteworthy policy change." Nordbeck and Steurer (2015) note that one of the more substantive Sustainable Development Strategy exercises was in the UK, where the policy was goal-oriented and a Sustainable Development Commission had an official watchdog 
function scrutinizing government strategy implementation, but a change of government saw the watchdog abolished.

Regarding measurement and evaluation, Steurer and Hametner (2013) note that the adoption of indicators as part of government sustainable development strategies in Europe has not been accompanied by the adoption of aggregated measures such as the Genuine Progress Indicator or the Index of Sustainable Economic Welfare. This they suggest is because of methodological concerns and to avoid "contested aggregation." These are surely valid concerns, but they suggest the challenge in creating a formulaic process to tackle tradeoffs between economic, social and environmental targets. The resistance to weighting in an index is precisely the resistance that would likely prevent a simple formula-based valuation of (as it might be) GDP growth against poverty reduction or CO2 output.

Most of the design weaknesses apparent in strategies and support institutions were against "best practice" suggestions by the OECD and others at the time, which suggested integrated strategies should link values, principles and objectives to specific measures and policy initiatives that would achieve them, and build in a monitoring, evaluation and reporting (Nordbeck and Steurer, 2015). In the light of this experience, Nordbeck and Steurer (2015) call for a less "heroic" approach, emphasizing sectoral governance around communication and capacity building, even though it is not clear the record suggests coordination limited to communication and capacity building leads to dramatic change. The lesson for sustainable development strategies going forward might instead be to actually follow "best practice" recommendations on design and evaluation from groups including the OECD.

Many countries outside of the European Union have also adopted Sustainable Development Strategies, or strategies that directly address elements of sustainable development, some with greater success. For example, the Energy Saving and Emission Reduction Policy of China, integrated with the $10^{\text {th }}$ and $11^{\text {th }}$ five year plans, appears to have been a significant factor behind lower SO2 and energy intensity in the country. 85 provinces of mainland China have seen output per unit of energy consumption climb and four provinces have seen a complete decoupling of GDP growth and energy growth in the 1997-2012 period, for example

(Zhang, 2016). This is evidence that Sustainable Development Strategies could have a greater impact if they are embedded in (binding) policy processes.

\section{Targeted Budgeting}

One approach to ensure strategy priorities are reflected in resource flows involves targeted budgeting. Janet Stotsky (2006) reviews the experience with gender budgeting, which involves using a gender lens to examine the differential impact of budget decisions on women and girls. Australia, for example, introduced a "women's budget" in 1987 where ministries and departments were expected to report on the gender-disaggregated impact of their spending. The effort was gradually abandoned, however, because it was not "sufficiently influential of policy to justify the work required to produce it." Stotsky suggests similar outcomes for an effort in South Africa. She argues that gender budgeting exercises need to ensure "tangible improvements in policy making and policy outcomes." 
A recent Nigerian experiment suggests how this might occur. The "Growing Girls and Women in Nigeria" (G-WIN) Program, run by the Finance Ministry, provided additional finance to line ministries that delivered results for gender equality. The Ministry of Health used the additional resources increase their capacity to deliver obstetric fistula surgery and the Ministry of Agriculture provided mobile phones to about 2 million female farmers to access information and agricultural content to improve their farming methods as well as allow mobile banking. ${ }^{11}$

A broader example is "performance budgeting," where government expenditure is focused on the achievement of particular outputs and outcomes - a model that would fit well with the target orientation of the SDGs. To date, experience with the approach is limited. OECD surveys of budget practice suggest that no OECD country in 2012 directly linked expenditures to performance, with performance measures used to inform rather than decide budget levels. If anything there has been a decline in the use of performance metrics as part of budget negotiations over the recent past, and they are an adornment rather than key feature of budgeting. Inertia and the (often legitimate) role of political influence are to account for this. ${ }^{12}$ In the US, after 2004, the Office of Management and Budget included performance and management assessments of programs as part of a tool to allocate budget resources. The scores did have some impact spending, but only in departments of the government that the incumbent party had proposed for closure or programs created by the party in opposition (Gilmour and Lewis 2006).

A linked process involves satellite accounts which augment the system of national accounts (which generate GNI statistics) to allow them to track the economic importance of activities they do not usually capture. They can record resource inputs, production and the means of production, and beneficiaries and results. Countries have produced satellite accounts for ICT, non-profit sectors, education, tourism, natural resources, and household activities (UK Office of National Statistics, 2008). Because they can help value activities and resources usually not valued in the national accounts (household labour, environmental resources), satellite accounts can provide a more accurate picture of the state of the (whole, sustainable) economy and the impact of policies on that economy. They can also help highlight crosssectoral links. As such they might be a powerful tool for informed decision-making in the SDG era, although it should be noted that there is little evidence (either way) on the impact of their production.

\footnotetext{
${ }^{11}$ http://www.worldbank.org/content/dam/Worldbank/document/Gender/Summary $\% 20$ of $\% 20$ Inaugural $\% 20$ Gender $\% 20$ Equality $\% 20$ Community $\% 20$ of $\% 20$ Practice $\% 20$ for $\% 20$ Finance $\% 20$ Ministers.pdf accessed 7/29/2016

12 The Metamorphoses of Performance Budgeting, presentation by Allen Schick prepared for the Annual OECD Meeting of Senior Budget Officials Paris, 3-4 June 2013 http://www.oecd.org/gov/budgeting/D2-AM\%20$\% 20$ Performance $\% 20$ budgeting $\% 20-\% 20$ Allen $\% 20$ SCHICK.pdf
} 


\section{Policy integration at the international level}

MDG8 included targets and indicators that spoke to broader policy coherence for development beyond rich country aid flows including trade, finance and technology. During the MDG period, there was slow progress towards OECD country duty free access for goods from the poorest countries as well as (overall) slightly lower agricultural commodities protection. And HIPC debt relief played some part in reducing the overall debt stock and service burdens. At the same time, this progress was slow and partial—against a backdrop of a failed decade of global trade negotiations at the WTO (Kenny and Dykstra, 2013). The extent to which MDG8 can be seen as the forcing mechanism for rapid progress is at most limited, then.

The OECD 2008 Ministerial Declaration supported efforts towards policy coherence for development and the OECD-DAC Peer Review mechanism has a section on "beyond aid" policies (Knoll, 2014). The OECD itself (2015) suggests that member countries efforts to monitor policy coordination for development have focused on institutional mechanismspolitical commitment, coordination mechanisms and monitoring and analysis. A greater focus on the actual impact of coordination would help develop lessons of experience for the purposes of improvement and global learning. It is also worth noting that OECD-driven processes including the Global Partnership for Effective Development Cooperation have not appealed to middle income donors.

The European Union translated the concept of "policy coherence for development" into a legal commitment as part of the Lisbon Treaty in 2009 although the language (the Union "shall take account of the objectives of development cooperation in the policies that it implements") is considered weak (Knoll, 2014). Steur and Hametner's (2013) review of the coherence of member state national sustainable development strategy objectives with the European Union sustainable development strategy of 2006 suggests considerable lack of coherence, particularly regarding global poverty and public health. They conclude "the EU failed to live up to its (perhaps overly) ambitious aim of vertical policy integration," and that the EU Sustainable Development Strategy itself, despite "an originally well-designed strategy process" deteriorated to "a more or less symbolic policy document."

Regarding outcomes, it is not clear that the legal commitment has had a significant impact in making EU policies more "development friendly," perhaps because it was worded in a general manner with little in the way of specific targets, processes or regulations to back it up. In 2012 Barder et al carried out analysis of EU policies towards developing countries covering trade, aid, finance, migration, the environment, security and technology using the Center for Global Development's Commitment to Development Index. The report suggested "In 2012, the European countries score a little above the global average, and over time Europe has gradually improved, doing roughly as well as Australia but always behind New Zealand and Canada. The United States has made more significant progress since $2008 \ldots$ If Europe considers that its commitment to development is exceptional, there is little sign of it here... There is little sign of any significant changes resulting from Europe's aspirations towards greater policy coherence and the commitments Europe has made in various international agreements, including the Millennium Declaration in 2000, the Paris 
Declaration on Aid Effectiveness, the G8 Gleaneagles agreement..." While scoring well in terms of aid quality and quantity, average EU country trade scores on the Commitment to Development Index (reflecting agricultural subsidies and tariffs on developing country imports) are below those for North America and technology scores (reflecting public good R\&D efforts as well as the strength of patent laws) are low. A brief scan of the CDI scores for larger EU countries since 2012 suggests this broad conclusion would not change. ${ }^{13}$

King et al. (2012) review the European experience and conclude that an index of policy coherence could "only be successfully realized if there is sufficient political will and a genuine interest among countries to be compared." They show that many European countries-along with OECD member states - are yet to demonstrate such will (having rejected the introduction of Policy Coherence for Development indicators in 2010 and 2009, respectively), which is why the one existing index of policy coherence they point to is produced by a non-government organization.

\section{Cross-Sectoral and Global Cost Benefit Analyses}

One path towards more radical change would combine a regulatory and prioritization approach that aimed to ensure policies and investments were selected on the grounds of their impact on sustainable development. Two models that have pointed in this direction are The Stern Review on the Economics of Climate Change and the Copenhagen Consensus exercise. A key feature of the Stern Review was to conduct a cost benefit analysis of climate change and responses that valued equally the welfare of individuals worldwide and into the future (making no preference on the account of nationality or time). The Copenhagen Consensus approach suggests prioritizing sustainable development investments across sectors and countries on the basis of cost-benefit analysis.

It is worth noting that, for all of their value in informing decision-making, such approaches are controversial, not least because of the lack of consensus over the valuation of both nonmonetary impacts and externalities as well as the technocratic rather than democratic policy process they would require if implemented as direct decision-making tools. Rather than short-circuiting democratic processes through such approaches, it would be preferable to persuade citizens and decision-makers that a greater weighting toward social, environmental and international factors was the right approach to begin with, and provide tools including cost-benefit analysis to help inform decisions based on that assumption.

\section{The Way Forward for Strategies and Policy Integration in Support of the 2030 Agenda}

As suggested by the widespread experience with MDG coordinating bodies, existing sustainable development strategies and efforts at integration, any effort to integrate policy around the SDGs will usually build on an existing integration infrastructure and policies.

\footnotetext{
${ }^{13}$ http://www.cgdev.org/cdi-2015 Accessed 7/12/2016
} 
This was very clear from the Voluntary National Reviews carried out in advance of the UN High Level Political Forum in 2016. For example, the Government of the Philippines (2016) nested its incorporation of the SDGs within a ten-point socioeconomic agenda, the Philippine Development Framework and the Long-Term Vision for 2040, and planned to utilize a range of existing institutions including the Cabinet Clusters on Human Development and Climate Change, the Social Development Committee and the Philippine Council for Sustainable Development to coordinate and monitor.

The Republic of Estonia (2016) noted that the country had passed a Sustainable Development Act in 1995 and a Sustainable Development Strategy in 2005, which included a set of monitoring indicators and was overseen by a Sustainable Development Commission of NGOs alongside an inter-ministerial working group on sustainable development. The government incorporated Agenda 2030 elements into this existing strategy framework. The Republic also noted in its submission that it was "already implementing measures" in the fields of all 17 SDGs.

Again, Uganda incorporated the SDGs into its National Development Plan, although the country did "improve institutional functionality" in response to the ambitious nature of SDGs by establishing a delivery unit in the Prime Minister's Office and the creation of a Government Evaluation Facility amongst other changes. And Germany has made its existing National Sustainable Development Strategy "a key framework for achieving the SDGs in Germany." The key principles of the strategy are intergenerational equity, quality of life, social cohesion and international responsibility. The government notes that the progress reports that update the strategy involve a broad-based process of dialogue and consultation, including public dialogue conferences held in all regions of the country and a three or fouryearly dialogue forum with NGOs, religious groups, local authorities and academics (Federal Republic of Germany, 2016).

While this existing strategy and infrastructure is welcome in that it reduces the institutional burden of creating new processes and procedures to manage integration, it also suggests the risk that policy integration efforts towards the 2030 agenda may amount to a marginal change around processes that have historically delivered mixed results.

Kemp et. al. (2005) sum up lessons from the mixed record of policy integration as follows: "only limited gains are possible through structural measures (creation of inter-ministerial committees and the like). Some further improvements can be won through structural changes tied to mandatory reporting and monitoring requirements." They suggest more significant progress requires common long-term objectives, planning and approval criteria, specific rules for making tradeoffs and widely accepted indicators.

The political plausibility of such elements is dependent on a significant communication and outreach effort led by those leaders who have committed their countries to deliver on sustainable development. The structural transformation that would be required by unprecedented progress will be opposed by powerful interest groups who will lose (at least relatively, and at least in the short term) from changes to tax regimes, public sector reform, opening to trade and migration and the diversion of significant financial flows. 
Leaders and officials who agreed the SDGs and are supporting their rollout to need convince stakeholder citizens of the need for radical reform in the face of this opposition. That will not be straightforward. For example, the common complaint of those interested in "broader measures of development" is that the most common narrow measure-GDP per capita - gets too much attention. However, poll evidence suggests a powerful reason why this may be the case-in countries rich and poor, jobs and the economy are the top concerns of citizens (Leo, 2013).

In this regard the German example of outreach appears a potential model to expand upon. Leaders will need to sell arguments around enlightened self interest and/or altruism. And policymakers themselves have to be convinced of the utility of the exercise: Asa Persson (2016) suggests policy integration "will never stick unless policy-makers, implementers and the electorate accept a new narrative - that is, they understand how the policy areas are linked and why the solutions should be coordinated and integrated. This takes time."

But even with greater consensus over prioritizing all three pillars of sustainable development, the process of prioritization and tradeoffs will remain deeply political. There is significant and legitimate disagreement over the impact of policies on development and sustainability. Few parliaments or presidents would propose policies that they would admit are "bad for development," and yet policies over time and across countries vary considerably. This may be in part because of the dominance of special interests but it also reflects real unknowns and differing preferences. In turn, this will make the "coherence" of policies contested. There is an active debate within the environmental movement between those who see nuclear power as a threat and those that see it as a vital part of the fight against climate change, for example (Sailor et al., 2000). Prioritization under such circumstances is necessarily and appropriately an issue for debate between stakeholders rather than the result of a technical prioritization process which, at best, is likely to be a useful input.

Regarding coordination, with multiple targets for policy and multiple policy-making bodies some of which are institutionally more concerned with particular targets, we cannot and should not expect "total policy integration"- the goal instead should be reasonable coordination to avoid strongly contradictory policies and regulations and promote those that are double or triple-win. To borrow a term from Merilee Grindle about governance (Grindle, 2004), what sustainable development efforts require is "good enough policy integration" - the condition of minimally acceptable government performance and civil society engagement that does not significantly hinder economic and social development while ensuring environmental sustainability.

Because coordination takes considerable time and institutional resources, prioritization of coordination efforts is important. Coordination can blur lines of accountability as well as measures of effectiveness and impact (Meijers and Stead, 2004). "Whole of Government" approaches which involve coordination exercises without the mandate and ability to significantly alter policy and regulation merely suck up bureaucratic time and capacity. They are policy integration as bureausclerosis and isomorphic mimicry rather than meaningful tools for promoting sustainable development. 
Meijers and Stead (2004) suggest a hierarchy of coordination mechanisms in which “integrated policy making sits atop a pyramid above policy coordination and policy cooperation, implying higher levels of interaction, formality, loss of autonomy and compatibility." The appropriate level of coordination should depend on the significance and tractability of the externalities linking the two institutions involved. But good enough policy integration would highlight "automatic" coordination mechanisms such as regulations, taxes and subsidies over coordination mechanisms that require complex institutional interactions. It would also prioritize the focus on coordination in areas where spillovers were the greatest.

If the choice is between an inter-ministerial committee to discuss fuel efficiency in agency car fleets and a tax on fuel, the second is likely to be more effective and less bureaucratically demanding. Policy integration should not primarily be about setting up new coordination bodies but putting in place the cross-cutting policies that ensure the multiple goals of development are automatically factored in because the incentive is there to do so. Again, need for coordination may be reduced if policy or technological innovation reduces negative (or increases positive) spill-overs between particular SDG target areas.

\section{A. Prioritizing Coordination Efforts}

Nilsson, Griggs and Visbeck (2016) suggest a national mapping exercise to score SDG targets on their interactions from the most positive (indivisible) through enabling to "consistent" (implying no significant interactions) and "constraining" to the most negative (cancelling). This might help as a prioritization exercise, but given there are 169 targets, it would involve scoring 14,365 potential interactions and as the authors suggest "many knowledge gaps will surface" during such an exercise that would need to take place at the country level because interactions will depend on broader country context. The mapping exercise should start with a considerably smaller subset of the targets prioritized by countries (perhaps on the grounds of representing broader goal areas), and integration efforts should be prioritized on interactions scored most positive or negative.

Annex One lays out one mechanism along these lines: analysis of the cross-country strength of relationships between outcome measures targeted by the SDGs. The Sustainable Development Solutions Network and Bertelsmann Stiftung have recently created a set of 77 indicators covering each of the 17 SDGs. Using this data, the Annex creates correlation matrix of all 77 indicators to examine strong positive $(0.75$ correlation) or negative $(-0.75$ correlation) relationships between these indicators. There are 155 correlations across the 5,852 relationships that meet this criteria, 126 of which cross goals. The analysis suggests the relevance of concepts like the water-food-energy nexus, for example, which highlights the deeply intertwined challenges of producing more food, more water and more energy for a larger, richer global population.

Figure Two graphically illustrates the strength of cross-goal relationships. In cases where at least some of the correlations between indicators in different goals are strongly positive or negative, squares are coloured grey. Where more than ten percent of relationships are either strongly positive or negative, the squares are coloured black. For example, at least some of the SDG 2 indicators are strongly correlated with at least some indicators for Goals 3, 4, 6, 
7, 9 and 10. More than ten percent of relationships between indicators in SDG 1 and indicators in Goals 3, 6, 7, 10,11, and 17 are strongly correlated.

These correlations might suggest one approach to direct the focus of efforts to exploit synergies (in the case of positive correlations between preferred outcomes) or limit tradeoffs (in the case of negative correlations between preferred outcomes). Note that strong correlations do not suggest a strong causal link in either direction. They may suggest and underlying factor is causal to both (electricity access and Internet use are so highly correlated because both are strongly determined by GDP per capita, for example).

The exercise should be taken as illustrative. The indicators selected are not nearly all of or only inclusive of those selected by the official UN process, nor will they match up with country-led indicator selection efforts. The method will miss many important but conditional links (as it might be a strong link between nutrition and literacy where schooling is high). For these reasons alone the process would be better run at the national level. But a country-level exercise might be a useful first step in exploring where and why the strongest links (positive or negative) between indicators of economic, social and environmental progress appear, and what that suggests about opportunities to exploit synergies or reduce tradeoffs.

\section{B. Managing Prioritization and Tradeoffs}

Prioritization will be required both because of limited resources and because both synergies and tradeoffs will occur. These will both cross targets (between job creation in energyintensive industries and carbon dioxide emissions as it might be) and occur within sectorsfor example, between providing a higher quality of health care to easily-reached but already comparatively well served urban populations or using the same resources to provide some lower level of care to a smaller number of isolated recipients.

The Sustainable Development Goals and related targets and indicators are ill-suited as a source of policy prioritization, designed as they are to reflect a universal, indivisible and comprehensive view of development progress. Furthermore, the underlying rationale of the Sustainable Development Goals is that we cannot reduce development progress to one indicator, while the underlying rationale of exercises like cost-benefit analysis is that we can reduce concerns to the money metric. That suggests imagining we can use a system like cost benefit to determine which tradeoffs are worth making may be antithetical to the underlying rationale for thinking about policy integration in the first place.

Nonetheless, there is a significant agenda to support better prioritization: to set minimum standards respecting environmental, social and economic considerations using regulation and safeguards; to ensure all three pillars of sustainable development are reflected in the price signals created by government through tax and subsidy mechanisms as well as budgeting decisions at the national and local level; and to provide a framework in which policies are examined from multiple perspectives in terms of their potential impact on broad-based development with potential synergies and tradeoffs are illustrated and provide a forum in which debate and discussion between different informed stakeholders can help to produce a legitimate direction for policymaking to take. 
In addition, the SDGs provide a basis on which to prioritize innovation in order to help reduce tradeoffs. To take the example of energy intensive jobs and carbon emissions, an obvious method to reduce the trade off is to roll out cheap renewable energy sources that allow energy-intensive jobs to be (closer to) emissions-free. An important role for policies around coordination should be to reduce these tradeoffs, which can be accomplished with incentives to ministries, local governments and the private sector to increase sustainable resource efficiency.

The next sections discuss the role of regulations, safeguards, taxes and subsidies as well incentives to ministries, local governments and the private sector that will improve policy coherence, encourage support for cross-sectoral investment in efficient outcomes and the development of lower-trade off solutions. Sustainable Development Strategies that advance reform in these areas will go a long way to improve prospects for rapid progress towards the Sustainable Development Goals.

\section{Regulation and Safeguards}

Regulations (and pricing policies) might be viewed as "bottom up" strategies for policy coordination as compared to "top down" bespoke policies initiated through national strategies and coordination boards. Both will be required, but (in particular) bespoke coordination efforts will use up limited capacity and resources of senior government officials.

The more that incorporation of incentives toward sustainable development can be simplified to a regulation or price signal, the better. For example, rights are a cross-cutting regulatory tool that can ensure minimum standards are observed in policymaking decisions across government-not least, compensation for expropriation, preservation of minimum health standards and equal access to justice and services. In an SDG agenda that calls for no-one to be left behind, universal rights have a particularly valuable role in ensuring policy coherence.

The regulatory process might also involve an instrument that could (at least temporarily) halt or reverse policies or policy change alongside major investments if it was demonstrated that they failed a certain hurdle rate of return which accounted for domestic social and environmental impacts as well as economic, social and environmental impacts when a standardized methodology was applied. Such a process should still be subject to review, but might demand additional scrutiny by the executive or legislative bodies. Kemp et al (2005) suggest environmental assessments provide a model for approval criteria, while compensation rules as well as net gain and loss calculations can help to reduce tradeoffs.

Related to this, the more that regulation can be about outputs or outcomes rather than inputs (emissions rather than production techniques, for example), the better. Inputs apply undifferentiated to all, and so may require heavy bureaucratic cost, policy change or investment that is at most tangentially or possibly not at all related to the target that is the justification for that regulation. 
As well as putting in place suitable regulations to ensure human rights are respected and minimum standards are met for social and environmental development, there is a role for governments to reduce some regulations where they stand in the way of sustainable opportunity. For example, many cities place limits on housing density. But higher density is associated with a lower environmental footprint, and helps poor people afford housing where the jobs are. ${ }^{14}$ In the US, inter-state migration has dramatically slowed over the past two decades in part thanks to a combination of mortgage interest tax relief and housing density regulation that prices internal migrants out of the neighbourhoods where the good jobs (and schools) are. This has been a significant factor behind rising inequality (Ganong and Shoag, 2012). Deregulation and more progressive taxation in this case could be a force for economic growth as well as greater equality. Similarly, an important part of China's recent strong economic performance has been the movement of 140 million people within the country-larger from poorer Western provinces to richer Eastern ones, where jobs and pay are better. The further relaxation of internal controls on movement will be an important part of continued pro-poor growth in the country.

\section{Making Taxes and Subsidies Work for Sustainable Development}

Finance Ministries have two very powerful tools to foster greater policy integration and relieve the tradeoffs between development priorities: taxation and subsidies. It is possible even for very poor countries to collect considerable tax as a percentage of GDP_Liberia's tax-GDP ratio is 21 percent, Tanzania's is 17 percent (Bhattacharya, 2016). More tax revenue reduces the tradeoffs within government regarding investment priorities but in order to ensure there is not a significant impact on jobs, poverty or economic growth those taxes need to be carefully designed. In the best of circumstances, taxes can deliver environmental, social and economic benefits.

Progressive broad-based income tax systems with few exemptions and a high collection rate are tools to achieve both financing and equity goals. Most developing countries are a long way from such systems - in Latin America and the Caribbean, for example, revenues from personal income tax average just 1.4 percent of GDP compared to 8.4 percent in developed countries. Tax deductions represent about 50 percent of effective tax collections in the region. Even the richest ten percent of the population region-wide see an average effective rate of below 4 percent. Uruguay is a sign of the rapid progress that can be achieved. Tax reform that left income tax free for two thirds of the population but introduced progressive income tax rates after that point with few deductions saw receipts increase from 0.9 to 2.4 percent of GDP over just two years, with the share paid by the highest income quintile climbing from 60.4 to 80.5 percent (Corbacho et al. 2013)

\footnotetext{
${ }^{14}$ Looking at the experience of German workers after mass layoffs, and comparing individuals who stay in the local labor market to movers, employment rates were around 15 percentage points higher for movers three years after the layoff (Findeisen et al 2015) http://econstor.eu/bitstream/10419/112908/1/VfS 2015 pid 234.pdf accessed $7 / 29 / 2017$
} 
There is a particular policy coordination payoff from taxing bads-goods with negative externalities including pollution. Taxes to correct environmental problems average 2.5 percent of GDP in Europe but only 1 percent in Latin America (Corbacho et al. 2013). Or take alcohol and tobacco taxes: tobacco use is the largest cause of preventable death and disease and death in the world, with smokers 2 to 4 times more likely to get coronary heart disease or strokes than non-smokers. The cost of smoking to the Chinese economy was estimated at around $\$ 30$ billion in 2008 and one quarter of Indian public health spending goes to treating tobacco related diseases. Tobacco taxes raise money and reduce smoking rates - a ten percent increase in the price of cigarettes leads to a four percent decline in consumption (Savedoff and Alwang 2015).

New ICT solutions make the introduction of taxes on externalities more straightforwardfor example, cheap transponders make congestion charging very simple. Santiago de Chile introduced congestion charging and has seen travel times cut by as much as 40 percent. As long as some of the resulting income is used to improve public transport, the effects of such taxes can be considerably progressive (Corbacho et al. 2013).

Subsidy reform is another area where a triple win for economic, social and environmental development can be achieved. Total fuels subsidies worldwide were worth $\$ 65$ billion in 2014, with ten fossil-fuel rich economies accounting for 90 percent of all subsidies. The comparatively low value of subsidies in part reflects price: as recently as 2012 they were worth $\$ 110$ billion. The externalities associated with these subsidies in terms of negative effects on climate are estimated at $\$ 44$ billion each year (Davis, 2016). A number of countries including the UAE and Saudi Arabia have recently reduced fuel subsidies with the aim of diversifying economies and relieving fiscal pressures. If it is done right, examples including Iran's suggest that fuel subsidy reform can also be a powerful tool for improved targeting of government assistance.

Iran has also shown that rapid and dramatic reform of subsidies is politically possible if well executed. In 2010, subsidized gasoline prices in the country were around $\$ 0.10$ per liter compared to a market price closer to $\$ 2.00$ per liter. On December 18, 2010, the country allowed the price of some energy and agricultural goods to rise by up to 20 times as subsidies on energy were removed. Nearly four out of five of the country's households were compensated for the higher prices they faced through compensatory payments that had been deposited in specially-created bank accounts

The distribution compensation payments allowed households to substitute non-fuel purchases for more expensive gasoline, increasing their welfare and helping to diversify an economy that was heavily oil-dependent. And by reducing energy use, the reform reduced negative local and global externalities related to fossil fuel consumption. Were all global fossil fuel subsidies removed, the IMF estimates global CO2 emissions would decrease by 13 percent. Reduced vehicle use would lower congestion, local particulate emission and rates of road traffic accidents, as well as encouraging a switch to public transport use that increases its sustainability and cost effectiveness (Benes et al 2015). 
Again, India has begun a program to replace poorly targeted expensive and leak-prone subsidies for a range of goods including diesel, rice, wheat, naphtha and iron ore (which cost a total of 4 percent of the country's GDP) with cash transfers targeted towards the country's most vulnerable. This will save money, increase the poverty-reducing impact of government support and reduce the unintended consequences of targeted subsidies. Over the period November 2014 to January 2015, the Indian government largely replaced a subsidy on LPG cylinders with direct payments to 150 million consumers across all 646 districts of the country. The subsidy cost $\$ 7.8$ billion, which was more than the central government spent on primary education in the country (Bhattacharjee, 2016)..$^{15}$ Thanks to the spread of mobile banking combined with the government's biometric ID system called Aadhaar, it is possible to provide cash support to even the poorest people in the country.

Such cash transfers have been repeatedly shown to be more effective at fighting poverty than subsidizing goods or providing in-kind support. ${ }^{16}$ Given the scale of existing subsidy programs in India, if they were reinvented as cash transfers to the country's poorest that would be enough to raise the expenditure of every household to that of a household at the 35th percentile of the income distribution - well above the country's poverty line. ${ }^{17}$ And putting conditions on those transfers can help increase the broader social and economic impact of the finance. A number of countries including Brazil (in the Bolsa Familia program) and Mexico (Opportunidades) which provide financial support to very poor households as long as they meet conditions such as keeping children enrolled in school and ensuring they are fully immunized. Beyond the positive impact of the cash itself, the conditions markedly improve the targeted outcomes - if at the risk of excluding those who fail to meet the conditions (Baird et al., 2011).

The number of countries where targeted conditional cash transfers via electronic payment is an increasingly viable tool for focused pro-poor spending in the pursuit of economic and social goals is rapidly growing. Eight in ten people in the developing world own a mobile phone. 73 countries allow citizens to pay tax online, 179 use digital systems for customs processing and 148 have some form of digital ID (World Bank, 2016). The range and reach of mobile applications has created new opportunities to provide direct financial support to even some of the world's most disadvantaged people in post-disaster environments at a very low overhead. In the aftermath of the recent devastating earthquake in Nepal, for example, the UNDP partnered with Microsoft to develop a smart-phone application that monitors reconstruction efforts and ensure families working on cash for work programs were paid accurately and on time (UNDP 2015).

It should be noted that cash transfers alone, at their current scale, are an inadequate strategy to ensure dramatic reductions in poverty and inequality. Across the great majority of people worldwide, the secret to prosperity is formal sector employment, and economic growth is required both to create those jobs and increase their remuneration. Furthermore, while cash

\footnotetext{
15 See https://www.iisd.org/gsi/node/852

16 See http://www.poverty-action.org/study/impact-unconditional-cash-transfers-kenya

${ }^{17}$ See http://indiabudget.nic.in/es2014-15/echapvol1-03.pdf
} 
transfers can increase the uptake of government services, they are blunt instruments to improve the quality of those services. But as a comparatively effective form of safety net spending, they have an important role to play.

\section{E. Re-orienting Ministries from Inputs to Outcomes}

Beyond regulatory reform and the better use of taxes and subsidies as tools of integrated policy making, rapid progress on sustainable development will require a dramatic improvement in the capacity of ministries to turn resources into outcomes. This implies that when developing strategies to achieve targets under the SDGs, ministries and strategy bodies should not limit themselves to thinking "what tool does this ministry have to achieve outcomes," but "what are the most cost-effective measures to achieve these outcomes." This involves re-orienting the incentives of ministries so that rather than being fundamentally concerned with inputs (budget, number of teachers, etc) they became more concerned with maximizing outputs (students who can read, healthy children).

To support such exercises and provide Ministries with the knowledge they need to maximize results, there is a need to expand cross-sectoral cost effective approaches and evidence (we want outcome $\mathrm{X}$, what is cheapest way to achieve it). To take an example within the education sector, in India, around a quarter of all teachers are absent from the classroom during unannounced visits, with an associated fiscal cost of $\$ 1.5$ billion. Improving school monitoring is both effective and cheap with regard to reducing absence so that it is a ten times more cost effective strategy to improve teacher-student contact time than is increasing the number of teachers (Muralidharan et al, 2016)

Looking at the importance of cross-sectoral cost-effectiveness approaches, the recent effort to find the most effective routes to reduced mortality and morbidity in developing countries provides some examples: of the "essential interventions" suggested to reduce reproductive, maternal, newborn and child health, three require community health posts heath centres or hospitals to deliver while five do not. Interventions including food supplements, immunizations, education on hand-washing and sanitation, and the distribution of insecticide treated bed-nets require low levels of training to provide (Black et. al. 2016). Other exercises looking at the determinants of child health in the poorest countries emphasize the role of factors outside the formal health system altogether (Kenny, 2011). If the health ministry was rewarded on the basis of results rather than inputs supplied by doctors and nurses, it would have a greater incentive to finance such interventions.

While the record of performance budgeting is weak to date, were ministries rewarded with larger budgets on the basis of performance-better learning outcomes or health-rather than the size of their bureaucracy or the size of the budget last year, this might incentivize far greater policy coordination.

Alternately or additionally, incentives could be provided for Sectoral Ministers to fund activities under the responsibility of another ministry if these activities are the most cost effective method to meet a sectoral development priority. For example, if the most effective tool to ensure learning outcomes is the use of same language subtitling on television shows, 
the Education Ministry might be incentivized (perhaps through a matching program run by the Finance Ministry) to support expenditures in the Culture or Media Ministry that provided subtitling services. Ministerial financial incentives could also be negative. Another example would be imposing an environmental "shadow price" when calculating the costs of an investment (as it might be, a discounted cost of carbon emissions) which line ministries would be forced to remit to the Treasury as part of their costs of construction.

That said, many of the objectives of government ministries are not as easy to quantify as life expectancy or (arguably) learning outcomes, including important public goods including national security and justice. And no government ministry is dedicated to achieving only one

target (health ministries should care about more than maximizing average life expectancy, for example). That suggests, in the best of cases, performance budgeting can be a partial tool open to significant debate.

\section{F. Supporting Subnational Innovation}

As noted in Colombia's presentation to the High Level Political Forum in 2016, subnational governments are vital to the achievement of the SDGs. The central government has focused its early efforts on ensuring that the SDGs are incorporated in subnational planning exercises (Government of Colombia, 2016). Not least, it is not just at the Ministerial level that policy integration measures can spur innovation that delivers better outcomes. Policy innovation can be increased through decentralization, improved data and demand (i.e. incentives). While decentralization carries real risk regarding capacity at local levels, it also provides a powerful tool for policy experimentation. Data allows policymakers to determine what has worked and demand in the form of incentives provides the motivation to act. An example is India's forests decentralized payments. In 2015, the Indian federal government introduced a payment system to state governments that included a $\$ 6$ billion allocation based on the level of forest cover in states-if forest cover rises, so will payments. ${ }^{18}$ Decentralized authority to the state level was combined with forest data and a multi-billion transfer to create the incentive for experiments in forest preservation.

Knowledge and information combined with decentralization can help citizens demand better services directly: Voucher schools in the Indian state of Andhra Pradesh provide education at a third of the cost of public schools while achieving better test results (Woodhead, et al (2013). Chile improved student learning at the fastest rate worldwide between 1995 and 2011 through publicly funded school choice backed with head teacher autonomy an all-student testing (Bravo, et al. 2010). Without any element of privatization, reimbursing schools based on the number of students they enrol (and confirming that data is accurate) creates competition amongst schools and an incentive to keep students engaged (World Bank 2004). ${ }^{19}$

\footnotetext{
18 See http://www.ideasforindia.in/article.aspx?article id=1449

${ }^{19}$ Note the data that matters is not always used and not everything that matters is easily measurable: the actual influence of money in politics, or teacher effort or teacher value added. Related to that, it often becomes harder to
} 


\section{G. Bringing in the Private Sector}

As well as local government, civil society and the private sector have a vital role to play in achieving the SDGs. The private sector will provide the services, jobs and economic growth that are central to reaching the SDGs, but it is also the source of most consumption. Innovations to support private sector in achieving the triple bottom line will be an important part of the 2030 agenda. Save the Children, UNICEF and the UN Global Compact have developed the Children's Rights and Business Principles based on existing standards and best practices covering issues from child labour to marketing and advertising. Again, the SDG Compass is a tool developed by GRI, the UN Global Compact and the World Business Council for Sustainable Development to help companies align with the SDGs.

Outcomes-based regulation and pricing signals discussed above can also help the private sector deliver jobs and economic growth with fewer costs in terms of environmental and social costs. In some cases, simply requiring the private sector to produce data and making that data public can improve outcomes. In China, publishing data on pollution from factories led to a declining pollution rate. In Chile, making banks report on the gender breakdown of their client base illustrated that women were an overlooked and underserved potential customer base - and banks responded by providing financial products better designed for the needs of female clients, considerably increasing the number of women with bank accounts.

There might also be an increased role for the private sector as service provider. Across the world, the link between overall health spending and outcomes like under-five mortality is weak. This is for many reasons, but Filmer et. al. (2000) suggest "institutional capacity is a vital ingredient in providing effective services. When this capacity is inadequate, health spending, even on the right services, may lead to little actual provision of services..." The same is true of education (World Bank 2004). This points to the importance of the policy environment in turning spending into results and suggests a role for competition-perhaps in some cases private competition.

While there can be some role for private provision to improve service quality and cost effectiveness where it can be competitively provided, the empirical evidence on impact is mixed (see, for example, Romero et. al. 2017 on private provision of schooling in Liberia). If anything, the evidence is even more inconclusive when it comes to natural monopolies. Around the developing world, private provision of water and energy is usually associated with improved supply quality, reduced operational losses and higher productivity. At the same time, the average impact on prices and rollout is underwhelming, suggesting private participation is no guarantee of access and affordability (Gassner et. al., 2007).

Alongside limited evidence of dramatic development impact, there are limits to the potential level of private financing. Over the past few years, private capital has provided 15 to 20 percent of total investment in infrastructure in developing countries-although the

measure well if the data starts being meaningfully used: use test outcomes to determine college entrance or teacher pay and the response is to teach to the test, learning be damned 
considerable bulk of that in Upper Middle Income nations and very little in low income economies. While there is space for that to continue in sectors including telecommunications and perhaps grow in energy, the very real barriers and issues with private finance including the need for very high returns related to high-risk long-life investments suggest that especially in the poorest countries it will remain a limited source.

This suggests the need for additional tools, including far greater information and release transparency, in order to improve outcomes and provide greater stability and assurance to private sector operators. In Slovakia, publishing full information about procurement and government contracts has raised the average number of bids on a government tender by one to two bidders and increased value for money. ${ }^{20}$ Such tools also help ensure competitive provision produces results in health and education services. With regard to (public or private) provision of health and education services, citizens and government officials need the information to judge provider performance: how many hours are teachers teaching, what do test scores suggest about the value added schools are providing, are doctors turning up and using approved protocols to diagnose disease, and so on. When combined with consumer choice and the flexibility of officials to respond to the data, there is some evidence that such an approach improves outcomes (Kenny, 2010).

\section{H. Global Commitment to Policy Integration}

Global cooperation for policy integration will be central to achieving rapid progress on sustainable development. The OECD (2015) has re-conceptualized "Policy Coherence for Development" for the Post-2015 period as a universal tool—not solely applying to donor countries in their dealings with poorer countries. This involves efforts by all countries to address the negative spillovers of domestic policies on long-term development prospects, increase government capacity to identify tradeoffs and reconcile domestic policy with international goals and foster synergies across economic, social and environmental policy areas.

This implies politically painful policy reforms for rich and poor countries alike, perhaps in particular around beggar-thy-neighbour policies that may work to increase local prosperity even if at the cost of global development progress. Examples include the rise of protectionist measures since the global financial crisis as well as implicit and explicit subsidies including tax breaks, grants and provision of infrastructure services at below cost to attract industries. There is a role for industrial policy to correct market failures including coordination failures, and there is also a major role for the developed world to support new pathways to prosperity through services industries that do not rely on a shrinking global manufacturing employment base. But as with all major policies and investments under a sustainable development strategy, such subsidies and protections should be examined from the point of view of both their domestic social, environmental and economic impact and their global impact. As suggested by numerous G-20 meetings, the rise of protectionism threatens global

\footnotetext{
${ }^{20}$ see http://www.cgdev.org/publication/ft/publishing-government-contracts-addressing-concerns-and-easingimplementation
} 
recession. ${ }^{21}$ And poor developing countries are those that can least afford a bidding war to attract industries.

Wealthy countries should still bear the greater responsibility to consider international spillovers and at the 2016 UN High Level Political Forum, reviews from wealthier countries did discuss at greater length the global impact of national policies as well as the role for international assistance. The Federal Government of Germany (2016) highlighted its Resource Efficiency Program and a policy on sustainable supply chains as examples of "taking responsibility for the global impacts of its actions at the national level" for example.

Nonetheless, we have seen that giving greater weight to the global impact of national policies has been perhaps the greatest weakness of existing European and OECD sustainable development strategies, with efforts to promote policy coherence for development having little appreciable impact on measures of European commitment to development for example. This will reflect in part the lack of strong domestic constituencies in favour of propoor trade policy, subsidy or migration reform, and an important part of delivering on the radical global progress demanded by the SDGs will be building up such constituencies.

Policy coherence aimed towards the Sustainable Development Goals would crucially have to take account of cross border and global spill-over impacts regarding beggar-thy-neighbour economic policies in tax, finance, migration, trade and intellectual property as well as impacts on global commons from biodiversity and oceans through global health and the climate. The good news is that many of these policies - especially around trade, migration and subsidies_-are mutually beneficial to reform, even if politically sensitive.

The European Union has moved towards forms of agricultural support that don't harm the revenue making potential of developing country farmers, for example. The Common Agricultural Policy is abolishing both production quotas and export refunds to subsidize EU farm prices on global markets (European Commission 2015). This is good for both the EU and for producers in developing countries.

Further steps in this direction could carry immense benefits. Full implementation of the W'TO Trade Facilitation Agreement could raise global GDP by up to $\$ 1$ trillion and create 21 million jobs (Hufbauer and Schott, 2013). A combination of improved trade facilitation and liberalization of services trade could add $\$ 850$ billion to the export earnings of developing countries alone ( $\$ 2.3$ trillion worldwide, as well as adding 34 million jobs). There is also evidence that trade liberalization has a positive impact on overall tax revenues despite lower tariff revenues thanks to indirect economic effects (Bhattacharya, 2016)

Again, if remittances from migration increased to achieve destination workforce growth of between 3 and 8 percent over 2010-2020 that would equal an extra \$75-\$183 billion in flows a year to developing countries in addition to more rapid economic growth in the developed

\footnotetext{
${ }^{21}$ See http://www.globaltradealert.org/ for a discussion of recent trade measures and a contrast with G-20 statements on the issue. Accessed 9/5/2016
} 
world. ${ }^{22}$ Full liberalization of the movement of people could increase global GDP between 66 percent and 148 percent with the current residents of developing countries the greatest winners (Clemens, 2011). In order to see the revolutionary progress required by the SDGs, revolutionary progress in globalization is a prerequisite.

It is worth highlighting it is not just in the area of economic exchange where global agreements help countries pass self-interested reforms. The number of countries introducing laws on domestic violence, for example, spiked around global and regional agreements on women including the Beijing Platform for Action, the CEDAW Optional Protocol and the Maputo Protocol (World Bank 2015). Perhaps this work could be expanded through global cooperation to remove remaining legal barriers to equality between women and men.

Such policies do not necessarily require a new coordination mechanism: the World Trade Organization already discusses issues around the movement of goods, services and people while there are international coordinating treaties on issues from climate change through biodiversity to infectious disease monitoring. Instead, it requires a stronger commitment from governments worldwide to utilize such mechanisms, overcome entrenched special interests and forge international agreement that will considerably increase the rate of global progress in SDG target areas.

Policy coherence-indeed simple common sense-also calls for adequate funding of global public goods. Estimated annual outlays for development-oriented global public goods facilities (from the non-country programs of WHO through UN peacekeeping to global environment and data) total around $\$ 14$ billion a year according to an estimate by Birdsall and Diofasi (2015). Approximately half of that sum is for peacekeeping while global environmental institutions receive $\$ 3.6$ billion and global health issues $\$ 2.2$ billion. To put that in context, World Bank estimates suggest global health spending at market rates is about $\$ 7.8$ trillion-suggesting expenditures on institutions supporting global public goods in health account for 0.03 percent of total health expenditures worldwide. ${ }^{23}$

Again, the international diffusion and creation of technology will be a vital part of ensuring the kind of unprecedented progress called for in the SDGs. This may particularly apply to technologies of global health, sustainable energy and agriculture, and productivity. This suggests the need for higher standards and prices prior to the award of a patent (to avoid "patent thickets") alongside tighter restrictions on what is considered patentable and (potentially) shorter monopoly terms.

But it also demands creative ways of incentivizing new technologies of particular use to people in developing countries. There is considerable scope for greater international collaboration and agreement on funding research in priority areas for sustainable

\footnotetext{
22 http://www.cgdev.org/blog/post-2015-1-trillion-financing-package Accessed 7/29/2016 https://piie.com/publications/papers/hufbauerschott20130422.pdf accessed 7/29/2016

${ }_{23}$ World Bank data accessed 6/21/2016 http://data.worldbank.org/. One example of a successful treaty agreements that merged environmental, social and economic considerations to produce a considerable global economic return was the Montreal treaty.
} 
development - including the proposed doubling of research expenditures on renewable announced by many of the world's largest countries at the Paris climate talks. ${ }^{24}$ Approaches should include support for research such as the Drugs for Neglected Tropical Diseases Initiative-which works on developing non-patented treatments for diseases including Chagas, paediatric HIV and malaria, alongside advance market commitments such as the GAVI commitment to buy $\$ 1.5$ billion-worth of pneumococcal vaccines suitable for use in developing countries at a fixed price of $\$ 3.50$ per shot (Kenny and Barder, 2015)

A full accounting of policy integration for global development would also take into account that achieving a similar absolute increase in living standards in developing countries is usually far cheaper than achieving it in rich countries - the cost of an extra year on life expectancy or a reduction in national poverty levels costs far less when the average life expectancy is 30 than when it is 80 or the national poverty line is $\$ 1$ a day rather than $\$ 15$. This suggests the potential role for a global income tax to transfer resources to where they would carry the highest return in terms of quality of life. While such a proposal may take more than the fifteen years of the 2030 agenda to agree, at least rich countries should live up to existing obligations to devote 0.7 percent of their income to Overseas Development Assistance.

\section{Measuring Policy Integration}

"Good enough policy integration" may also involve the search for "good enough indicators" to measure progress. Grindle (2004) notes that the Zambia Poverty Reduction Strategy Paper listed a number of governance indicators including the advance of decentralization, the proportion of women parliamentarians and popular perceptions of corruption to measure progress towards governance goals but "whether they are appropriate measures for knowing if in fact government is performing better is a matter for considerable discussion." This is an issue that is likely to plague measures of policy integration in particular.

In addition, according to Knoll (2014), the way in which policy coherence is operationalized "varies widely and is very much part of the political culture and nature of administration systems within different countries"- - there is no one-size fits all approach. Policy Coherence for Development "is fundamentally a matter of politics," suggests Knoll. Policy coherence tool-kits may help but presenting them as technical fixes risks introducing yet another "boxticking exercise" to bring about development. ${ }^{25}$

For this reason, an authoritative list of "best practice" integration institutions and models is likely to remain chimerical. And while there are many cases of previous efforts of policy coordination from which to draw, there are no accepted metrics to measure relative success

\footnotetext{
${ }^{24}$ Global agreements to reign in the use of antibiotics in livestock and better moderate use in human medicine, introduce tiered pricing in global drug markets so that poorer consumers pay less for life saving drugs or access to information and knowledge.

${ }^{25}$ Note also leaders in fragile states, for example, may quite rationally prioritize short-term stability-building measures over longer-term sustainability measures on the grounds that no progress will be sustained without peace.
} 
of policy integration efforts. Instead, it is perhaps easier to take cases where clear double or triple-win policies have been introduced and trace back some of the political and institutional arrangements that allowed them to emerge.

This suggests a focus on measurable outcomes may be the more appropriate strategy for measuring the extent of integration. The purpose of policy integration is to allow for more rapid progress across the goals and targets of the SDGs. This suggests that policy integration efforts might be best measured by progress towards SDG targets. First: is the policy integration process fostering faster progress towards all targets? But, second, are synergies being maximized and the cost of tradeoffs minimized? Are target areas which are particularly positively inter-twined seeing progress in one area associated with the rapid progress that should be expected in the other area? Conversely, in target areas of tradeoffs, is progress in one area being associated with only limited impact in the other area?

To take a simplified but concrete example: there are positive inter-linkages from GDP growth to poverty reduction and health but traditional tradeoffs between economic growth and greenhouse gas emissions. Policy coherence is designed to maximize the outcomes achieved at a given resource level while benefiting from interlinkages and minimizing harmful spillovers. This suggests successful policy integration will see strong rates of progress in all four target areas but also particularly high "returns" from economic growth in terms of rapid poverty reduction and improved health alongside a comparatively weak response of greenhouse gas emissions to that economic growth. If returns to poverty reduction or health are low, or if greenhouse gas emissions climb, that suggests a policy coherence failure.

To move to an example of an indicator pointing to such policy coherence failure: worldwide, the ten countries that have the greatest levels of carbon dioxide output per unit of GDP produce 8.4 kilograms of $\mathrm{CO} 2$ for each $\$ 10$ of output, compared to a global country average of 2.6 kilograms. One policy coherence factor behind this is obvious. The IMF has data on post-tax energy subsidies for eight of those ten countries, and all are amongst the most significant subsidizers worldwide. The countries are are Bosnia and Herzegovina (post-tax energy subsidies that total 38 percent of GDP), Kazakhstan (10 percent), South Africa (12 percent), Ukraine (51 percent), Mongolia (15 percent), Uzbekistan (34 percent), Turkmenistan (29 percent), and Trinidad and Tobago (14 percent). ${ }^{26}$

To take another example, some countries do far better at ensuring investments in girls' education lead to high female labour force participation and (through that) stronger economic performance. In a sample of richer countries (GNI per Capita PPP $>\$ 5,000$ ) with data on female labour force participation and gross secondary enrolment, there is a clear relationship between the two (Figure 1). ${ }^{27}$ Some countries perform particularly badly, however, suggesting a considerable wasted investment. The five countries with less than one

\footnotetext{
${ }^{26} \mathrm{IMF}$ energy subsidy data from http://www.imf.org/external/pubs/ft/survey/so/2015/new070215a.htm accessed 7/8/2016 Carbon dioxide emissions data from World Bank

27 Angola excluded as outlier
} 
half the female labour force participation that would be predicted given their girls' enrolment rate are Qatar, Oman, Algeria, Jordan and Iran. There are a number of reasons for this, but one factor will be that these countries all have laws in place that significantly and specifically curtail women's abilities to participate in the workforce. These laws limit such basic rights as the ability to travel outside the home, the right to get a job or pursue a trade or profession, the right to sign a contract, the right to register a business, or the right to open a bank account (Kenny 2015). Without reform of such laws, policy coherence between social and economic objectives will remain significantly limited (to say nothing of the ability to meet gender equality targets within the SDGs).

It is important to note that a considerable number of factors beyond policy coherence efforts will have played a role in generating such outcomes-policy innovation more broadly, external factors, the country's different starting points and so on. Again, the importance of policy coherence to different outcomes varies across indicators, and not all indicators are easily measured. But to the extent we believe that policy coherence is a significant element in the story of achieving the revolutionary progress called for in the SDGs, over time policy coherence efforts should be observable in actual rates of target progress and the relationship between them under sustainable development strategies.

One possible way to measure broad-based success in policy coherence at the national level would be to create a synthetic indicator that amalgamates economic, social and environmental measures: a composite of GDP per capita, the poverty rate, and CO2 emissions, as it might be. The challenge to any such measure is weighting and inclusiveness, but to the extent weighting matches national prioritization of different areas of sustainable development, this might be acceptable. As noted, to date, countries following sustainable development strategies have not been able to agree such an indicator. ${ }^{28}$ In the best of circumstances, it should probably be an advisory tool rather than a policy target.

A disaggregated tool for measuring the success of policy integration in terms of reducing trade-offs and increasing synergies would be to take the correlations from the country-level prioritization exercise described above and monitor the strength of relationships between different indicators of progress over time. If negative correlations (suggesting tradeoffs) weakened while positive correlations (suggesting synergies) strengthened, this might be taken as an indication of improved policies and technologies that allow more rapid and universal progress across the domains of sustainable development. For example, policy coordination around the removal of fuel subsidies and the rollout of cheap renewable sources of power should be reflected in a weakening relationship between growing GDP per capita and increased carbon dioxide output (decoupling).

\footnotetext{
28 There are also risks with over-complex tracking processes. Meadowroft and Steurer (2013) note that EU countries track from 12 (France) to more than 100 (UK, Italy) sustainable development indicators but "large sustainable development indicators sets may be too complex to provide meaningful feedback for policymakers." Furthermore, very few countries justify their choice of indicators and the linkages among strategy objectives and indicators are rarely made explicit.
} 
Measuring policy integration at the international level would take additional indicators. Currently, the only such cross-country measure is the (unofficial) Commitment to Development Index produced by the Centre for Global Development. This only covers wealthy countries. A Commitment to Sustainable Development measure suited to the sustainable development goals would at the least have to have global coverage. It would include measures of: barriers to the movement of goods, finance, people and technology; beggar thy neighbour subsidies for industry and agriculture; membership of global governance mechanisms such as the UN Convention on the Law of the Sea; contributions to global public goods including research and development, finance for international organizations and overseas development assistance, and provision of peacekeeping forces; and contributions to global bads including subsidy of carbon dioxide emissions and low vaccination rates or limited implementation of international health regulations. Note any collection of measures and any weighting measure would be arbitrary, arguable and imperfect (as is the case with the Commitment to Development Index).

\section{J. Data for Integration and Innovation}

In regard to data for tracking and evaluating policy coordination and integration, of the recent list of 230 indicators selected to monitor SDG implementation, only 42 percent have been labeled "Tier 1" by the IAEG-SDG process, meaning that there is an established and clear methodology to collect the data, the data is collected and is widely and regularly available. Even amongst this set there are serious gaps: for example, only 37 percent of UN member states have produced $\$ 1.90$ poverty data since 2000 . The UN official MDG database recorded two or more national level poverty data points between 2000-2013 for just 19 out of 55 fragile states according to a recent survey (Save the Children, 2016). The Republic of Estonia (2016) estimates that of 231 global sustainable development indicators they reviewed, 86 percent are not currently measurable in the country.

Colombia provides an example of policy change linked to better monitoring of an SDG target: the country did not previously collect data on food waste, but did so last year to discover it was at over 30 percent. This sparked national debate and legislation to address the challenge. It is a sign of the considerable payoff that could follow far more intensive exercises to collect sustainable development data. And if policymakers are to use data as a tool to ensure progress, monitor experimentation and focus on results, they will need significant subnational data on at least an annual basis for a range of indicators beyond poverty. ${ }^{29}$

\footnotetext{
${ }^{29}$ Need wherever possible Objective indicators: Most studies on project-based aid effectiveness rely on subjective evaluation ratings to measure projects' performance. Using the example of drinking water projects, this study compares evaluation ratings to objective, quantitative project indicators based on water supply to better understand the drivers of evaluation ratings. We find that evaluation ratings are only weakly correlated with improvements in water supply. Whereas the water supply-based project indicators are best explained by project design variables, evaluation ratings put more weight on project management and implementation http://onlinelibrary.wiley.com/doi/10.1002/jid.3189/full
} 
The ICT revolution provides the opportunity for far more rapid and far cheaper collection of data. Analysis by Leo et al (2015) suggests that in countries with a reasonable level of phone coverage, phone surveys are comparable in quality to traditional house to house survey instruments while costing far less. As more countries reach ubiquitous phone coverage, this should allow for a considerably reduced cost of information collection. The Nigeria MDG Information System (NMIS) employed surveyors equipped with smart phones to collect information on 30,000 schools clinics and water systems across the country and upload data for analysis (Save the Children, 2016). Similarly, head teachers in Uganda are using a mobile phone application to transmit data on teacher attendance in a program that has reduced absenteeism by 11 percent (World Bank 2016). ${ }^{30}$ But, more broadly, given the need for policy innovation and learning to achieve rapid progress on the SDGs, improved data gathering capacity is a prerequisite of more rapid progress towards sustainable development.

\section{Conclusions and Recommendations}

The SDGs call for unprecedented global progress, but they also call for that progress to be sustainable. Both requirements demand a far more effective conversion of resources into development outcomes, and that suggests governments, as the key drivers of national and international progress, follow integrated policy paths that maximize positive spillovers and shrink the scale of tradeoffs. This will involve dramatic policy reform-from tax through subsidy to regulation and decentralization to open borders and larger transfers-as well as the commitment to collaborate across departments and across borders far more closely than in the past. The political and practical challenges to such change are likely to be considerable, and the role for "best practice solutions" surely limited, suggesting the need for realism in what will actually be achieved in the next twelve years.

That said, in order to accelerate progress towards the Sustainable Development Goals through greater policy integration, countries might consider five recommendations:

1. Focus coordination efforts in areas where synergies and tradeoffs are empirically the largest. Use price signals, taxes, regulation and deregulation as tools of comparatively low-friction sustainable development coordination.

2. Incorporate strategy and coordination into government financial cycles, ensuring significant fiscal incentives for cross-ministerial cooperation, the provision of global public goods, and local government innovation towards sustainable progress as well as priority investments, tax and subsidy reforms that align fiscal policy with sustainable development strategy.

3. Re-orient ministries towards outcomes instead of budgets and staffing, rewarding departments for financing results rather than providing inputs, and providing financial incentives for ministries to support cross-department and international expenditures.

${ }^{30}$ RCTs feedback loops (data) 
4. Prioritize policy reforms in areas which (a) empirical analysis suggests are particularly closely related to multiple sustainable development targets, for example the abandonment of fossil fuel subsidies and the reform of safety net payments to ensure better targeting and effectiveness and/or (b) reduce beggar-thy-neighbour policies such as trade and migration barriers or (most) industrial and agricultural subsidies.

5. Ensure national statistical agencies have the capacity to accurately monitor progress towards sustainable development targets but also deliver information that decision makers and citizens need to evaluate progress at the local level. Legally commit agencies to the monitoring of economic, social and environmental progress. 


\section{Bibliography}

Baird, S., McIntosh, C., \& Özler, B. (2011). Cash or condition? Evidence from a cash transfer experiment. The Quarterly Journal of Economics, qjr032.

Barder, O. M., Clark, J., Lépissier, A., Reynolds, L. E., \& Roodman, D. (2012). Europe beyond aid: assessing Europe's commitment to development. Center for Global Development Working Paper, (313).

Beaman, L., Duflo, E., Pande, R., \& Topalova, P. (2012). Female leadership raises aspirations and educational attainment for girls: A policy experiment in India. science, 335(6068), 582-586.

Benes, K., Cheon, A., Urpelainen, J., \& Yang, J. (2015). Low Oil Prices: An Opportunity for Fuel Subsidy Reform. New York: Columbia University.

Berger, G., \& Steurer, R. (2009). Horizontal policy integration and sustainable development: Conceptual remarks and governance examples. ESDN Quarterly Report June.

Bhattacharjee, G. (2016) Treat the Disease not the Symptom in Singh et al. (eds) Indian Economy: A Roadmap Toards Development Flying Pen Jaipur

Bhattacharya, D (2016) Post-2015 International Development Agenda in the Context of Interlocking Trade and Financing in the LDCs E15 Expert Group on Trade Finance and Development Think Piece, CID Harvard.

Birdsall, Nancy, and Anna Diofasi. "Global Public Goods for Development: How Much and What For." Centre for Global Development, Washington DC(2015).

Black, R. E., Levin, C., Walker, N., Chou, D., Liu, L., Temmerman, M., \& Group, D. R. A. (2016). Reproductive, maternal, newborn, and child health: key messages from Disease Control Priorities 3rd Edition. The Lancet.

Buvinic M. et. al. (2016) Comments at event How Multilateral Development Banks Track Gender Equality, held at the Center fdor global Development Washington DC, Thursday June 9, accessed http://www.cgdev.org/event/how-multilateral-developmentbanks-track-gender-equality

Charles Kenny and Owen Barder. 2015. "Technology, Development and the Post-2015 Settlement." CGD Policy Paper 063. Washington DC: Center for Global Development

Clemens, M. A. (2011). Economics and emigration: Trillion-dollar bills on the sidewalk?. The Journal of Economic Perspectives, 25(3), 83-106.

Corbacho, A., Cibils, V., \& Lora, E. (Eds.). (2013). More than Revenue: Taxation as a development tool. Springer.

Das, J., Holla, A., Das, V., Mohanan, M., Tabak, D., \& Chan, B. (2012). In urban and rural India, a standardized patient study showed low levels of provider training and huge quality gaps. Health affairs, 31(12), 2774-2784.

Davis, L. W. (2016). The Environmental Cost of Global Fuel Subsidies (No. w22105). National Bureau of Economic Research.

Department of Economic and Social Affairs United Nations (DESA) (2015) Policy integration in government in pursuit of the sustainable development goals Report on the expert group meeting held on 28 and 29 January 2015 at United Nations Headquarters New York

ECOSOC (2016) Implementing the 2016 Agenda: moving from commitments to results, Integration Segment, Implementing the 2030 Agenda for sustainable development 
through policy innovation and integration 2-4 May 2016, Conference Room Paper, New Work: United Nations

European Commission (2015) Policy Coherence for Development: 2015 EU Report European Commission Brussels SWD(215) 159 final

Filmer, Deon, Jeffrey S. Hammer, and Lant H. Pritchett. "Weak links in the chain: a diagnosis of health policy in poor countries." The World Bank Research Observer 15.2 (2000): 199-224.

Findeisen, S., Dauth, W., \& Lindner, A. (2015). What Are The Returns To Regional Mobility? Evidence From Mass Layoffs. In Annual Conference 2015 (Muenster): Economic Development-Theory and Policy (No. 112908). Verein für Socialpolitik/German Economic Association.

Ganong, P., \& Shoag, D. (2012). Why Has Regional Income Convergence in the US Stopped?. Social Science Research Network.

German Federal Government (2016) Report of the German Federal Government to the High-Level Political Forum on Sustainable Development 2016 Berlin: Federal Republic of Germany

Gilmour, J. B., \& Lewis, D. E. (2006). Does performance budgeting work? An examination of the office of management and budget's PART scores. Public Administration Review, 66(5), 742-752. Gilmour, J. B., \& Lewis, D. E. (2006). Does performance budgeting work? An examination of the office of management and budget's PART scores. Public Administration Review, 66(5), 742-752.

Glassman, A., \& Temin, M. (2016). Millions Saved: New Cases of Proven Success in Global Health. Brookings Institution Press.

Government of Colombia (2016) Voluntary National Review at the 2016 High Level Political Forum On the Sustainable Development Goals. Bogota: Government of Colombia

Government of the Philippines (2016) Voluntary National Review at the 2016 High Level Political Forum On the Sustainable Development Goals. Nature, 534, 320-322. Manila: Government of the Philippines

Grindle, M. S. (2004). Good enough governance: poverty reduction and reform in developing countries. Governance, 17(4), 525-548.

Hassan, Fadi, and Paolo Lucchino. "Powering education." Acta Tropica 17 (2014).

Hufbauer, G., \& Schott, J. (2013). Payoff from the World Trade Agenda 2013. Peterson Institute for International Economics, 9.

International Resource Panel (UNEP) (2015) "Policy Coherence of the Sustainable Development Goals: A Natural Resource Perspective."

Jeffrey Hammer, Dean Spears, Village sanitation and child health: Effects and external validity in a randomized field experiment in rural India, Journal of Health Economics, Volume 48, July 2016, Pages 135-148

Kemp, R., Parto, S., \& Gibson, R. B. (2005). Governance for sustainable development: moving from theory to practice. International Journal of Sustainable Development, 8(12), 12-30.

Kenny C\& Dykstra, S. (2013). The global partnership for development: A review CGD Policy Paper 
Kenny C. and Megan O'Donnell. 2016. "Do the Results Match the Rhetoric? An Examination of World Bank Gender Projects." CGD Policy Paper 077. Washington DC: Center for Global Development. http://www.cgdev.org/publication/do-resultsmatch-rhetoric-examination-world-bank-gender-projects

Kenny, C. (2010). Learning about schools in development. Center for Global Development Working Paper, (236).

Kenny, C. (2012). Getting Better: why global development is succeeding--and how we can improve the world even more. Basic Books.

Kenny, C. (2014). The upside of down: why the rise of the rest is good for the West. Perseus Books Group.

Kenny, C. (2015) A US Law or Executive Order to Combat Gender Apartheid at Work in Discriminatory Countries, Center for Global Development Policy Note

Kenny, C., \& Sumner, A. (2011). More money or more development: what have the MDGs achieved?. Center for Global Development working paper, (278).

King, M., Keijzer, N., Spierings, E., \& Matthews, A. (2012). Measuring Policy Coherence for Development. Maastricht: European Centre for Development Policy Management.

Knoll, A. (2014). Bringing policy coherence for development into the post-2015 agendachallenges and prospects. Maastricht: ECDPM (Discussion Paper No. 163).

Kothari, B., Takeda, J., Joshi, A., \& Pandey, A. (2002). Same language subtitling: a butterfly for literacy?. International Journal of Lifelong Education,21(1), 55-66.

Le Blanc, D. (2015). Towards integration at last? The sustainable development goals as a network of targets. Sustainable Development, 23(3), 176-187.

Leo, B. (2013). (2016). Policy: Map the interactions between Is Anyone Listening? Does US Foreign Assistance Target People's Top Priorities?. Center for Global Development Working Paper, (348).

Leo, B., Morello, R., Mellon, J., Peixoto, T., \& Davenport, S. T. (2015). Do Mobile Phone Surveys Work in Poor Countries?. Center for Global Development Working Paper, (398).

Levy, B. (2014). Working with the grain: integrating governance and growth in development strategies. Oxford University Press.

Meadowcroft, J. (2007). National sustainable development strategies: Features, challenges and reflexivity. European Environment, 17(3), 152-163.

Meadowcroft, J., \& Steurer, R. Republic of Uganda (2016) Review Report on Uganda's Readiness for Implementation of the 2030 Agenda Kampala: Republic of Ugandfa

Meijers, E., \& Stead, D. (2004, December). Policy integration: what does it mean and how can it be achieved? A multi-disciplinary review. In Berlin Conference on the Human Dimensions of Global Environmental Change: Greening of Policies-Interlinkages and Policy Integration. Berlin.

Mullan, K. (2014). The Value of Forest Ecosystem Services to Developing EconomiesWorking Paper 379.

Muralidharan K. et al. (2016) The Fiscal Cost of Weak Governance World Bank Policy Research Working Paper 7579

Nilsson, M., Griggs,Nordbeck, R., \& Steurer, R. (2015). Multi-sectoral strategies as dead ends of policy integration: Lessons to be learned from sustainable 
development.Environment and Planning C: Government and Policy, $0263774 X 15614696$.

Noon, Barry R., and Kevin S. McKelvey. "Management of the spotted owl: a case history in conservation biology." Annual Review of Ecology and Systematics (1996): 135-162.

OECD (2015) Better Policies for Development: Policy Coherence and Green Growth, Paris, OECD

OECD(2008) Policy Coherence for Development—Lessons Learned OECD Policy Brief.

ONE (2015)The 2015 Data Report: Putting the Poorest First Washington DC: ONE

Persson, A. (2016)Policy integration: don't break down those silos just yet Deliver2030.org post, June 22 2016: http://deliver2030.org/?p=6996

Pritchett, L., Banerji, R., \& Kenny, C. (2013). Schooling is not education! Using assessment to change the politics of non-learning. Center for Global Development Report.

Pritchett, L., Woolcock, M., \& Andrews, M. (2013). Looking like a state: techniques of persistent failure in state capability for implementation. The Journal of Development Studies, 49(1), 1-18.

Republic of Estonia (2016) Review on the Implementation of the 2030 Agenda in Estonia, Talinn: Republic of Estonia

Reza Farzin, M., Guillaume, D. M., \& Zytek, R. (2011). Iran-the chronicles of the subsidy reform. IMF Working Papers, 1-28.

Romero, M., Sandefur, J., \& Aaron, W. (2017). Can Outsourcing Improve Liberia’s Schools?.CGD Working Paper 462.

Sachs, J. D., \& VisbeckSchmidt-Traub, G., \& Durand-Delacre, D. (2016). Preliminary Sustainable Development Goal (SDG) Index and Dashboard. SDSN Working Paper, 15 February.

Sailor, W. C., Bodansky, D., Braun, C., Fetter, S., \& van der Zwaan, B. (2000). A nuclear solution to climate change?. Science, 288(5469), 1177.

Save the Chldren (2016) From Agreement to Action: Delivering the Sustainable Development Goals London: Save the Children

Savedoff, B. and A. Alwang (2015) The Single Best Health Policy in the World: Tobacco Taxes CGD Policy Paper 62.

Schmidt-Traub, G., \& Shah, A. (2015). Investment Needs to Achieve the Sustainable Development Goals. Paris and New York: Sustainable Development Solutions Network.

Steurer, R., \& Hametner, M. (2013). Objectives and indicators in sustainable development strategies: similarities and variances across Europe.Sustainable Development, 21(4), 224 241.

Stotsky, J. G. (2006). Gender budgeting. IMF Working Papers, 1-50.

Sundaram, J. K., Chowdhury, A., Sharma, K., \& Platz, D. (2016). Public-Private Partnerships and the 2030 Agenda for Sustainable Development: Fit for purpose? DESA Working Paper No. 148.

Tessa Bolda , Deon Filmerb , Gayle Martinc , Ezequiel Molinad , Brian Stacye , Christophe Rockmoref, Jakob Svenssong, and Wally Waneh (2016) What Do Teachers Know and Do? A Report Card on Primary Teachers in Sub-Saharan Africa, World Bank Policy working Paper forthcoming.

UK Office of National Statistics (2008) Proposals for Satellite Accounts, May 2006 
UNCTAD (2015) Improving Market Access for the Least Developed Countries in the 2030 Agenda for Sustainable Development Post-2015 Policy Brief 6.

UNDP (2015) Innovation for 2030 UNDP Innovation Facility 2015 Year in Review

United Nations Economic and Social Council (2015) Mainstreaming a gender perspective into all policies and programmes in the United Nations system, Report of the Secreary General report E/2015/58

Vivalt, E. (2015). Heterogeneous Treatment Effects in Impact Evaluation.American Economic Review, 105(5), 467-70.

Wiedmann, T. O., Schandl, H., Lenzen, M., Moran, D., Suh, S., West, J., \& Kanemoto, K. (2015). The material footprint of nations. Proceedings of the National Academy of Sciences, 112(20), 6271-6276.

World Bank (2013) World Development Report 2013: Jobs.Washington DC: World Bank

World Bank (2015) Women Business and the Law 2016: Getting to Equal, Washington DC: World Bank

World Bank (2016) World Development Report 2016 Digital Dividends.Washington DC: World Bank

World Bank. (2004). World Development Report 2004: Making Services Work for Poor People. World Bank.

Zhang, Z., Xue, B., Pang, J., \& Chen, X. (2016). The decoupling of resource consumption and environmental impact from economic growth in china: Spatial pattern and temporal trend. Sustainability, 8(3), 222. 
Figure One: Female Education and Labor Force Participation

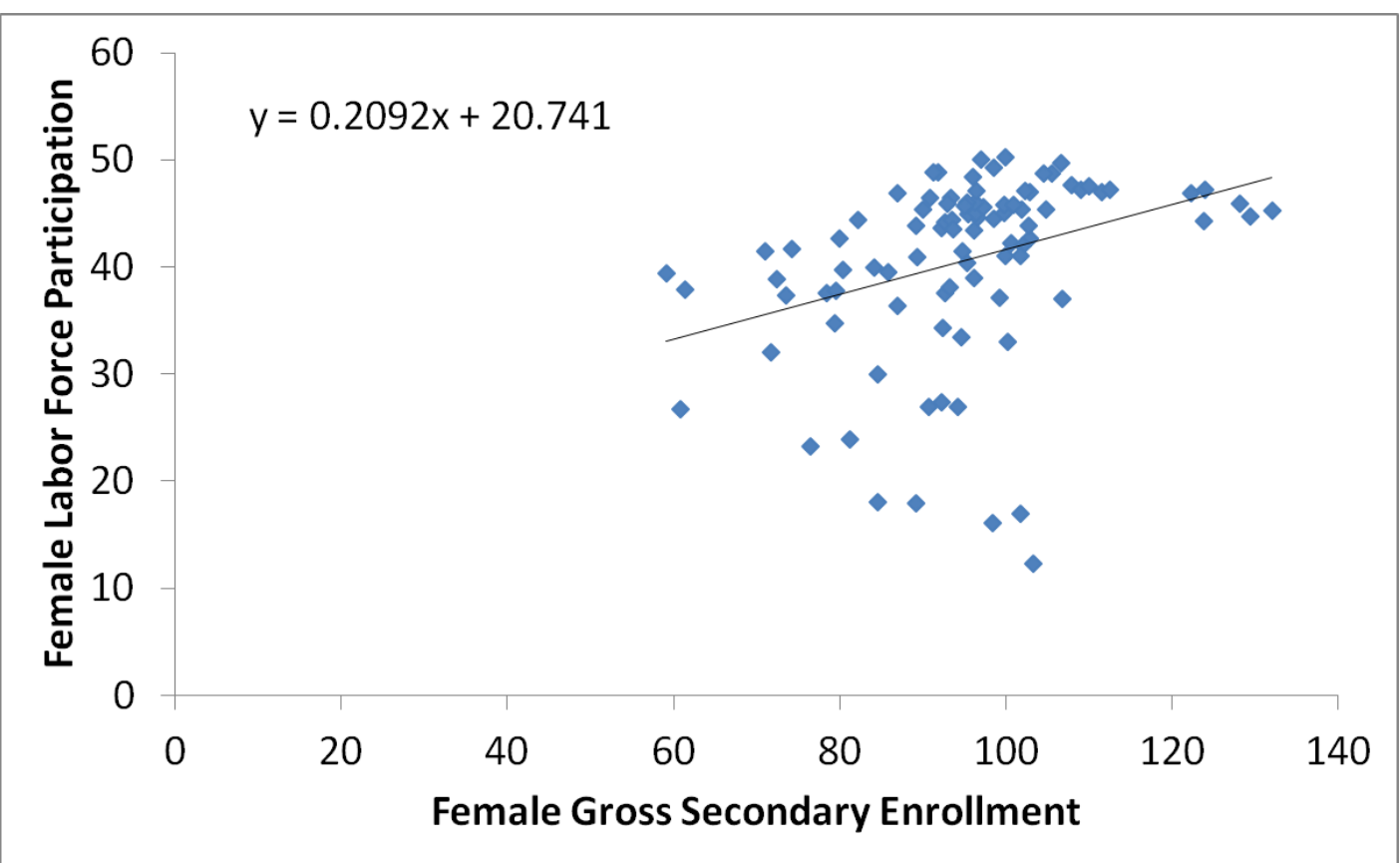

Figue Two : Correlation Between SDG Indicators at the Goal Level

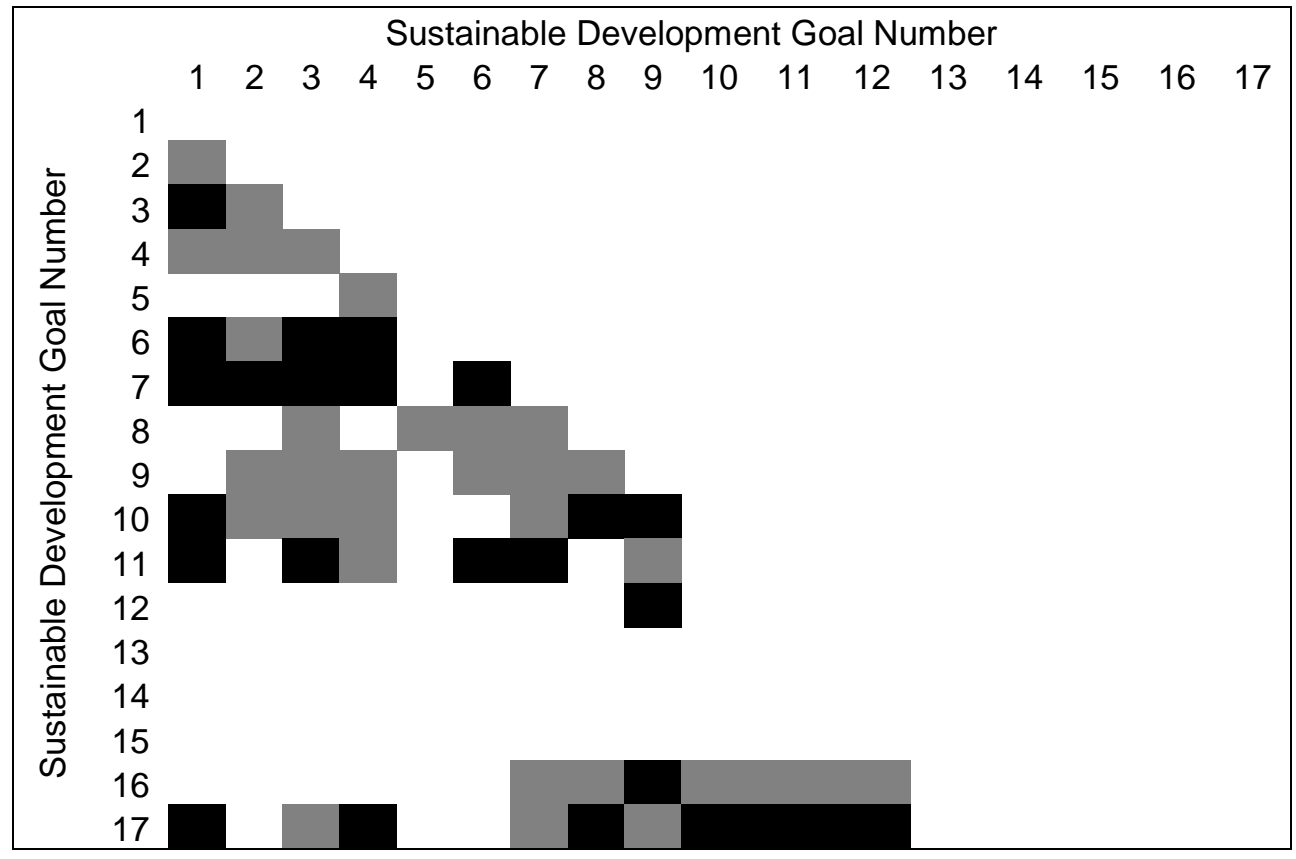




\section{Annex 1: Correlation between SDG Index Components}

The Sustainable Development Solutions Network and Bertelsmann Stiftung have recently created an "SDG Index" attempting to measure progress towards the SDGs at the country level. ${ }^{31}$ The SDG Index uses a set of 77 indicators covering each of the 17 SDGs (listed in Annex Table I below). Where possible, the SDG Index uses the official indicators proposed by the IAEG-SDGs but where official indicators have insufficient data available or there are gaps, other metrics selected by the report team were included.

For the correlation analysis, we took the raw data provided by the Index and created correlation matrix of all 77 indicators. Those correlations which were above 0.75 (suggesting a strong positive relationship) or below -0.75 (suggesting a strong negative relationship) are reported in Annex Table Two. Indicators are only listed if they have at least one significant positive or negative correlation. Annex Table Three repeats the results excluding in-Goal correlations. There are 155 correlations across the 5,852 relationships that meet this criteria, 126 of which cross goals.

These correlations might suggest at the cross-country level, one approach to measure the focus of efforts to exploit synergies (in the case of positive correlations between preferred outcomes) or limit tradeoffs (in the case of negative correlations between preferred outcomes) should lie. Note a caution in interpretation of the table: a negative correlation between poverty and access to improved sanitation (as it might be) counts as a synergy, while a positive correlation between one positive indicator of sustainable development and another negative indicator counts as a tradeoff. Note also that strong correlations do not suggest a strong causal link in either direction. They may suggest and underlying factor is causal to both (electricity access and Internet use are so highly correlated because both are strongly determined by GDP per capita, for example).

The exercise and table should be taken as illustrative. First, the indicators listed are often not those of the official SDG process, and are arguable (not least, use of total rather than per capita CO2 emissions). Second, the process will miss many important but conditional links (as it might be a strong link between nutrition and literacy where schooling is high). Third, the process would be better run at the national level wherever possible - tradeoffs and synergies will vary between countries because of these conditional links.

Nonetheless, a country-level exercise might be a useful first step in exploring where and why the strongest links (positive or negative) between indicators of economic, social and environmental progress appear, and what that suggests about opportunities to exploit synergies or reduce tradeoffs. Top-down coordination efforts can then focus in on the set where these opportunities are greatest.

The exercise might also help point to "nexus" areas. For example, there are a group of strong correlations suggested between SDG 3 and SDGs 4,6, 7 and 11-with 26 strong

${ }^{31}$ Report and data available here: http://sdgindex.org/download/ 
correlations within that space. That speaks to the strong links between health, education, energy and water. 


\section{Indicators Used in Analysis}

\section{Goal 1}

Poverty headcount ratio at $\$ 1.90$ a day (2011 PPP) (\% of population)

Poverty rate after taxes and transfers, poverty line $50 \%$ ( $\%$ of population)

\section{Goal 2}

Prevalence of undernourishment (\% of population)

Cereal yield ( $\mathrm{t} / \mathrm{ha})$

Prevalence of stunting (low height-for-age) in children under 5 years of age (\%)

Prevalence of wasting in children under 5 years of age $(\%)$

Sustainable Nitrogen Management Index (0-1)

Prevalence of obesity, BMI $\geq 30$ (\% of adult population)

\section{Goal 3}

Mortality rate, under-5 (per 1,000 live births)

Maternal mortality rate (per 100,000 live births)

Neonatal mortality rate (per 1000 live births)

Physician density (per 1000 people)

Incidence of tuberculosis (per 100,000 people)

Traffic deaths rate (per 100,000 people)

Adolescent fertility rate (births per 1,000 women ages 15-19)

Subjective wellbeing (average ladder score, 0-10)

Healthy life expectancy at birth (years)

Percentage of surviving infants who received 2 WHO-recommended vaccines (\%)

Daily smokers (\% of population aged $15+)$

\section{Goal 4}

Expected years of schooling (years)

Literacy rate of 15-24 year olds, both sexes (\%)

Net primary school enrolment rate $(\%)$

Population aged 25-64 with tertiary education (\%)

PISA score $(0-600)$

Population aged 25-64 with upper secondary and post-secondary nontertiary educational attainment $(\%)$

\section{Goal 5}

Proportion of seats held by women in national parliaments (\%)

Female mean years of schooling of population aged 25 and above ( $\%$ of male)

Female labor force participation rate ( $\%$ of male)

Estimated demand for contraception that is unmet (\% of women married or in union, ages $15-49)$ Gender wage gap ( $\%$ of male median wage)

\section{Goal 6}

Access to improved water source (\% of population) 
Access to improved sanitation facilities (\% of population)

Freshwater withdrawal ( $\%$ of total renewable water resources)

\section{Goal 7}

Access to electricity ( $\%$ of population)

Access to non-solid fuels ( $\%$ of population)

$\mathrm{CO} 2$ emissions from fuel combustion and electricity output (MtCO2/TWh)

Share of renewable energy in total final energy consumption

\section{Goal 8}

Unemployment rate ( $\%$ of total labor force)

Automated teller machines (ATMs per 100,000 adults)

Adjusted growth rate (\%)

Youth not in employment, education or training (NEET)

Percentage of children 5-14 years old involved in child labor (\%)

Employment-to-Population ratio (\%)

\section{Goal 9}

Logistics Performance Index: Quality of trade and transport-related infrastructure (1-5)

Quality of overall infrastructure (1-7)

Mobile broadband subscriptions (per 100 inhabitants)

Proportion of the population using the internet $(\%)$

Patent applications filed under the PCT in the inventor's country of residence (per million population)

\section{Goal 10}

Gini index (0-100)

Palma ratio

PISA Social Justice Index (0-10)

\section{Goal 11}

Annual mean concentration of particulate matter of less than 2.5 microns of diameter (PM2.5) $(\mu \mathrm{g} / \mathrm{m} 3)$ in urban areas

Rooms per person

Improved water source, piped ( $\%$ of urban population with access

\section{Goal 12}

Percentage of anthropogenic wastewater that receives treatment $(\%)$

Municipal solid waste (kg/year/capita)

Non-recycled municipal solid waste $(\mathrm{kg} /$ person/year)

\section{Goal 13}

Energy-related CO2 emissions per capita (tCO2/capita)

Climate Change Vulnerability Monitor (0-1) 


\section{Goal 14}

Ocean Health Index Goal - Clean Waters (0-100)

Ocean Health Index Goal - Biodiversity (0-100)

Ocean Health Index Goal - Fisheries (0-100)

Marine sites of biodiversity importance that are completely protected (\%)

Percentage of fish stocks overexploited or collapsed by EEZ (\%)

\section{Goal 15}

Red List Index of species survival (0-1)

Annual change in forest area (\%)

Terrestrial sites of biodiversity importance that are completely protected (\%)

\section{Goal 16}

Homicides (per 100,000 people)

Prison population (per 100,000 people)

Proportion of the population who feel safe walking alone at night in the city or area where they live. $(\%)$

Corruption Perception Index (0-100)

Proportion of children under 5 years of age whose births have been registered with a civil authority, by age $(\%)$

Government efficiency (1-7)

Property rights (1-7)

\section{Goal 17}

For high-income and all OECD DAC countries: International concessional public finance, including official development assistance ( $\%$ of GNI)

For all other countries: Tax revenue (\% of GDP)

Health, education and R\&D spending (\% of GDP) 


\section{High-Correlation Indicators from the SDSN SDG Index}

\begin{tabular}{|c|c|c|c|c|c|c|c|c|c|c|c|c|c|c|c|c|c|c|c|c|c|c|c|c|c|c|c|c|c|c|c|c|c|c|c|c|c|c|}
\hline & 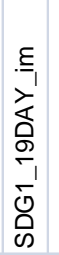 & 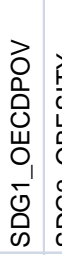 & 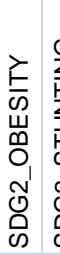 & 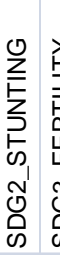 & 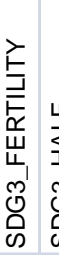 & 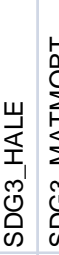 & 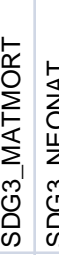 & 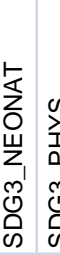 & 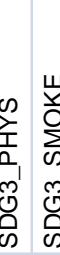 & 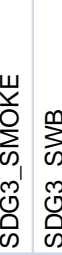 & 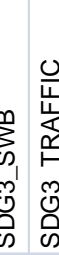 & 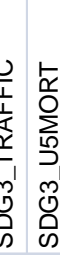 & 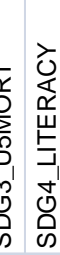 & 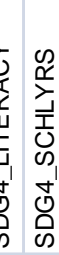 & 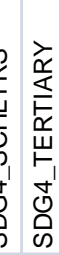 & 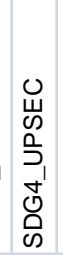 & 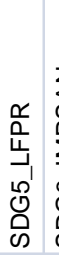 & 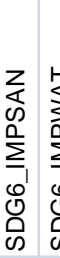 & 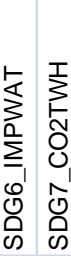 & 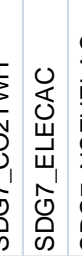 & 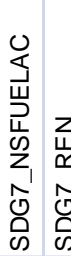 & & 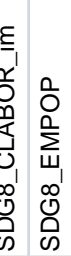 & 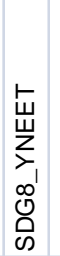 & 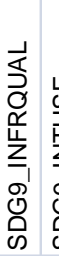 & 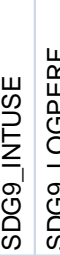 & 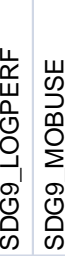 & 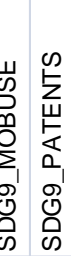 & 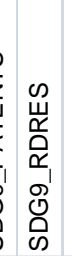 & 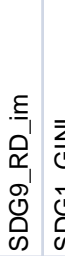 & 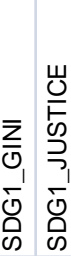 & 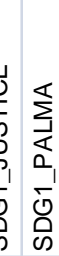 & 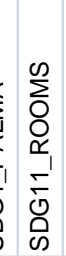 & 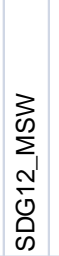 & 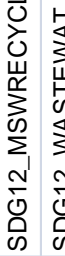 & 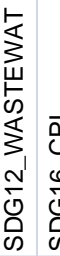 & $\begin{array}{l}\bar{a} \\
U_{1} \\
0^{\prime} \\
y^{\prime} \\
0 \\
\text { c }\end{array}$ & 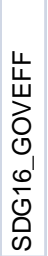 \\
\hline SDG2_STUNTING & 1 & & & & & & & & & & & & & & & & & & & & & & & & & & & & & & & & & & & & & \\
\hline SDG3_FERTILITY & 1 & & & & & & & & & & & & & & & & & & & & & & & & & & & & & & & & & & & & & \\
\hline SDG3_HALE & -1 & & & & -1 & & & & & & & & & & & & & & & & & & & & & & & & & & & & & & & & & \\
\hline SDG3_MATMORT & 1 & & & & 1 & -1 & & & & & & & & & & & & & & & & & & & & & & & & & & & & & & & & \\
\hline SDG3_NEONAT & & & & 1 & 1 & -1 & 1 & & & & & & & & & & & & & & & & & & & & & & & & & & & & & & & \\
\hline SDG3_SWB & & & & & & 1 & & & & & & & & & & & & & & & & & & & & & & & & & & & & & & & & \\
\hline SDG3_TRAFFIC & & & & & & -1 & & & & & & & & & & & & & & & & & & & & & & & & & & & & & & & & \\
\hline SDG3_U5MORT & 1 & & & & 1 & -1 & 1 & 1 & & & & & & & & & & & & & & & & & & & & & & & & & & & & & & \\
\hline SDG4_LITERACY & -1 & & & . & & & -1 & -1 & & & & & -1 & & & & & & & & & & & & & & & & & & & & & & & & & \\
\hline SDG4_SCHLYRS & & & & -1 & & 1 & & -1 & & & & & 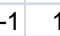 & 1 & & & & & & & & & & & & & & & & & & & & & & & & \\
\hline SDG4_UPSEC & & & & 1 & & & & & & & & & & & & & & & & & & & & & & & & & & & & & & & & & & \\
\hline SDG5_EDAT & & & & & & & & & & & & & & 1 & & & & & & & & & & & & & & & & & & & & & & & & \\
\hline SDG6_IMPSAN & -1 & & & -1 & -1 & 1. & -1 & -1 & & & & & $-1 \quad 1$ & $\begin{array}{lll}1 & 1 & r\end{array}$ & 1 & & & & & & & & & & & & & & & & & & & & & & & \\
\hline SDG6_IMPWAT & -1 & & & & & 1 & & -1 & & & & & -1 & & & & & 1 & & & & & & & & & & & & & & & & & & & & \\
\hline SDG7_CO2TWH & & & & & & & & & & & & & & & & & & & & & & & & & & & & & & & & & & & & & & \\
\hline SDG7_ELECAC & -1 & & & -1 & -1 & 1. & -1 & -1 & & & & & 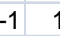 & 11 & 1 & & & 1 & 1 & & & & & & & & & & & & & & & & & & & \\
\hline SDG7_NSFUELAC & -1 & & 1 & -1 & & 1. & -1 & -1 & & & & & -1 & & 1 & & & 1 & 1 & 1 & & & & & & & & & & & & & & & & & & \\
\hline SDG8_CLABOR_im & & & & & 1 & -1 & & & & & & & & & & & & -1 & & -1 & -1 & & & & & & & & & & & & & & & & & \\
\hline SDG8_EMPOP & & & & & & & & & & & & & & & & & 1 & & & & & & & & & & & & & & & & & & & & & \\
\hline SDG8_YNEET & & & & & & & & & & & & & & & & & & & & & & & -1 & & & & & & & & & & & & & & & \\
\hline SDG9_INTUSE & & & & -1 & & 1 & & -1 & 1 & & $1-$ & $\begin{array}{lll}-1 & -1 & -1\end{array}$ & -1 & & 1 & & & 1 & & 1 & 1 & & \begin{tabular}{l|l}
-1 & 1 \\
\end{tabular} & -1 & 1 & & & & & & & & & & & & & \\
\hline SDG9_LOGPERF & & & & & & & & & & & & & & & & & & & & & & & & & 1 & 1 & & & & & & & & & & & & \\
\hline SDG9_MOBUSE & & & & & & & & & & & & & & & & & & & & & & & & & & 1 & 1 & & & & & & & & & & & \\
\hline SDG9_RD_im & & & & & & & & & & & & & & & & & & & & & & & & & & & 1 & 1 & 11 & & & & & & & & & \\
\hline SDG1_GINI & & 1 & & & & & & & & & & & & & & & & & & & & & & & & & & & & & & & & & & & & \\
\hline SDG1_JUSTICE & & & & -1 & & & & & & & 1 & & & & & & & & & & & & 1 & -1 & 1 & 1 & & 1 & & 1 & & & & & & & & \\
\hline SDG1_PALMA & & 1 & & & 1 & & 1 & & & & & & & -1 & & & & & & -1 & & & 1 & & & & & & & & 1 & & & & & & & \\
\hline SDG11_PIPEDWAT & -1 & & & & & 1 & -1 & -1 & & & & & -1 & & 1 & & & 1 & 1 & 1 & 1 & & & & & 1 & & & & & & & & & & & & \\
\hline SDG11_ROOMS & & & & & & & & & & & & & & & & & & & & & & & & & & & 1 & & & & & & & & & & & \\
\hline SDG12_MSWRECYCL & & & & & & & & & & & & & & & & & & & & & & & & & & & & & & & & & & 1 & & & & \\
\hline SDG12 WASTEWAT & & & & & & & & & & & & & & & & & & & & & & & & & 1 & 1 & 1 & & & 1 & & & & & & & & \\
\hline SDG16_CPI & & & & & & & & & & & & & & & & & & & & & & & 1 & -1 & 1 & 1 & 11 & 1 & & & & 1 & 1 & & & 1 & & \\
\hline SDG16_PRS & & & & & & & & & & & & & & & & & & & & & & & & & 1 & & & & & & & 1 & & & & & 1 & 1 \\
\hline SDG16_U5REG & & & & & & & & & & & & & & & & & & & & 1 & & & & & & & & & & & & & & & & & & \\
\hline SDG17_GOVREV & & -1 & & & & & & & & 1 & & & & & -1 & 1 & & & & & & 1 & -1 & 1 & & & & 1 & 1 & & & $1-1$ & 11 & & 1 & & & \\
\hline SDG17_GOVSPD & & & & & & & & & & & & & & & & & & & & & & & & & & & & & & & & 1 & & & & & & \\
\hline
\end{tabular}




\section{High-Correlation Indicators from the SDSN SDG Index Excluding in-Goal Correlations}

\begin{tabular}{|c|c|c|c|c|c|c|c|c|c|c|c|c|c|c|c|c|c|c|c|c|c|c|c|c|c|c|c|c|c|c|c|c|c|c|c|c|c|c|}
\hline & 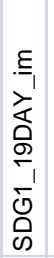 & 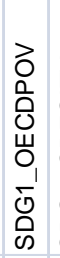 & 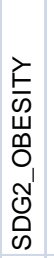 & 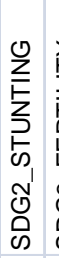 & 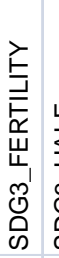 & 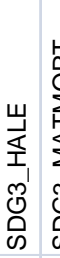 & 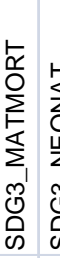 & 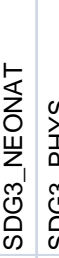 & 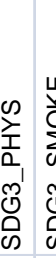 & 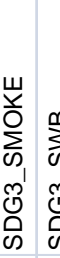 & 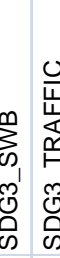 & 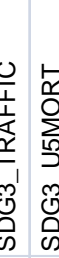 & 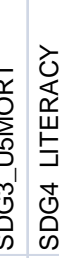 & 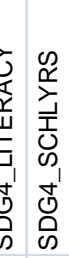 & 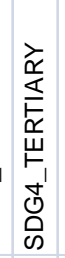 & $\begin{array}{l}u \\
\text { W } \\
0 \\
د \\
J^{\prime} \\
0 \\
\text { 心 }\end{array}$ & 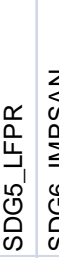 & 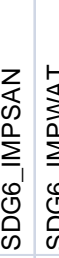 & 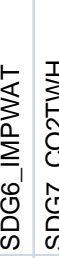 & 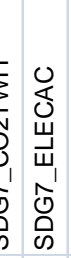 & 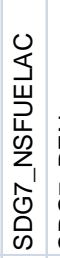 & 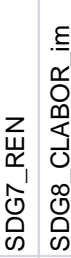 & 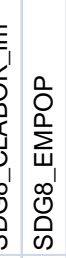 & 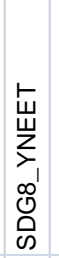 & 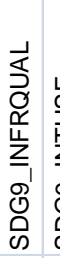 & 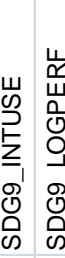 & 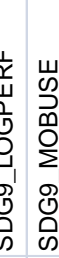 & 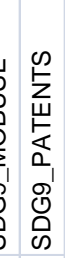 & 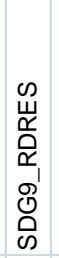 & $\begin{array}{l}\Xi_{1} \\
0^{\prime} \\
\sigma_{1} \\
\delta^{\prime} \\
0 \\
0\end{array}$ & 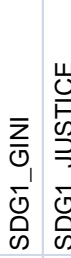 & 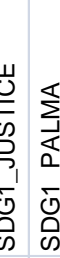 & 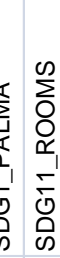 & 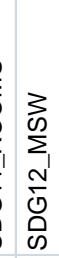 & 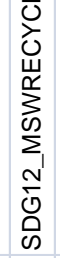 & 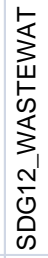 & $\begin{array}{l}\overline{0} \\
0_{1} \\
0 \\
-1 \\
0 \\
0\end{array}$ & 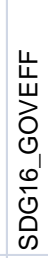 \\
\hline SDG2_STUNTING & 1 & & & & & & & & & & & & & & & & & & & & & & & & & & & & & & & & & & & & & \\
\hline SDG3_FERTILITY & 1 & & & & & & & & & & & & & & & & & & & & & & & & & & & & & & & & & & & & & \\
\hline SDG3 HALE & -1 & & & & & & & & & & & & & & & & & & & & & & & & & & & & & & & & & & & & & \\
\hline SDG3_MATMORT & 1 & & & & & & & & & & & & & & & & & & & & & & & & & & & & & & & & & & & & & \\
\hline SDG3_NEONAT & & & & 1 & & & & & & & & & & & & & & & & & & & & & & & & & & & & & & & & & & \\
\hline SDG3_SWB & & & & & & & & & & & & & & & & & & & & & & & & & & & & & & & & & & & & & & \\
\hline SDG3 TRAFFIC & & & & & & & & & & & & & & & & & & & & & & & & & & & & & & & & & & & & & & \\
\hline SDG3_U5MORT & 1 & & & & & & & & & & & & & & & & & & & & & & & & & & & & & & & & & & & & & \\
\hline SDG4_LITERACY & -1 & & & & & & -1 & -1 & & & & & -1 & & & & & & & & & & & & & & & & & & & & & & & & & \\
\hline SDG4 SCHLYRS & & & & -1 & & 1 & & -1 & & & & & -1 & & & & & & & & & & & & & & & & & & & & & & & & & \\
\hline SDG4_UPSEC & & & & 1 & & & & & & & & & & & & & & & & & & & & & & & & & & & & & & & & & & \\
\hline SDG5_EDAT & & & & & & & & & & & & & & 1 & & & & & & & & & & & & & & & & & & & & & & & & \\
\hline SDG6_IMPSAN & -1 & & & -1 & -1 & 1 & -1 & -1 & & & & & -1 & $\begin{array}{lll}1 & 1 & r\end{array}$ & & & & & & & & & & & & & & & & & & & & & & & & \\
\hline SDG6_IMPWAT & -1 & & & & & 1 & & -1 & & & & & -1 & & & & & & & & & & & & & & & & & & & & & & & & & \\
\hline SDG7_CO2TWH & & & & & & & & & & & & & & & & & & & & & & & & & & & & & & & & & & & & & & \\
\hline SDG7 ELECAC & -1 & & & -1 & -1 & 1 & -1 & -1 & & & & & -1 & $1 \quad 1$ & & & & 1 & 1 & & & & & & & & & & & & & & & & & & & \\
\hline SDG7_NSFUELAC & -1 & & 1 & -1 & & 1 & -1 & -1 & & & & & -1 & 1 & & & & 1 & 1 & & & & & & & & & & & & & & & & & & & \\
\hline SDG8_CLABOR_im & & & & & 1 & -1 & & & & & & & & & & & & -1 & & -1 & -1 & & & & & & & & & & & & & & & & & \\
\hline SDG8_EMPOP & & & & & & & & & & & & & & & & & 1 & & & & & & & & & & & & & & & & & & & & & \\
\hline SDG8_YNEET & & & & & & & & & & & & & & & & & & & & & & & & & & & & & & & & & & & & & & \\
\hline SDG9_INTUSE & & & & -1 & & 1 & & -1 & 1 & & 1 & $-1-$ & -1 & 1 & & & & 1 & & 1 & 1 & -1 & $\begin{array}{ll}-1 & 1\end{array}$ & -1 & & & & & & & & & & & & & & \\
\hline SDG9 LOC & & & & & & & & & & & & & & & & & & & & & & & & & & & & & & & & & & & & & & \\
\hline SDG9 MOBUSE & & & & & & & & & & & & & & & & & & & & & & & & & & & & & & & & & & & & & & \\
\hline SDG9_RD_im & & & & & & & & & & & & & & & & & & & & & & & & & & & & & & & & & & & & & & \\
\hline SDG1_GINI & & 1 & & & & & & & & & & & & & & & & & & & & & & & & & & & & & & & & & & & & \\
\hline SDG1 JUSTICE & & & & -1 & & & & & & & 1 & & & & & & & & & & & & 1 & -1 & 1 & 1 & & 1 & & & & & & & & & & \\
\hline SDG1_PALMA & & 1 & & & 1 & & 1 & & & & & & -2 & -1 & & & & & & -1 & & & 1 & & & & & & & & & & & & & & & \\
\hline SDG11_PIPEDWAT & -1 & & & & & 1 & -1 & -1 & & & & & -1 & 1 & & & & 1 & 1 & 1 & 1 & & & & & 1 & & & & & & & & & & & & \\
\hline SDG11 ROOMS & & & & & & & & & & & & & & & & & & & & & & & & & & & 1 & & & & & & & & & & & \\
\hline SDG12 MSWRECYC & & & & & & & & & & & & & & & & & & & & & & & & & & & & & & & & & & & & & & \\
\hline SDG12_WASTEWAT & & & & & & & & & & & & & & & & & & & & & & & & & 1 & 1 & 1 & & & 1 & & & & & & & & \\
\hline SDG16 CPI & & & & & & & & & & & & & & & & & & & & & & & 1 & -1 & 1 & 1 & 1 & 1 & & & & 1 & 1 & & & 1 & & \\
\hline SDG16 PRS & & & & & & & & & & & & & & & & & & & & & & & & & 1 & & & & & & & 1 & & & & & & \\
\hline SDG16_U5REG & & & & & & & & & & & & & & & & & & & & 1 & & & & & & & & & & & & & & & & & & \\
\hline SDG17 GOVREV & & -1 & & & & & & & & 1 & & & & & -1 & 1 & & & & & & 1 & -1 & 1 & & & & 1 & 1 & & & $1-$ & $-1 \quad 1 \quad$ & & 1 & & & \\
\hline SDG17_GOVSPD & & & & & & & & & & & & & & & & & & & & & & & & & & & & & & & & 1 & & & & & & \\
\hline
\end{tabular}


